\title{
From Neural Crest Development to Cancer and Vice Versa: How p75 NTR and (Pro)neurotrophins Could Act on Cell Migration and Invasion?
}

\author{
Sabine Wislet ${ }^{1 *}$, Geoffrey Vandervelden ${ }^{1}$ and Bernard Rogister ${ }^{1,2}$ \\ ${ }^{1}$ GIGA-Neurosciences, University of Liège, Liège, Belgium, ${ }^{2}$ Department of Neurology, University of Liège, Liège, Belgium
}

\section{OPEN ACCESS}

Edited by:

Ashok K. Shetty,

Texas A\&M College of Medicine,

United States

Reviewed by:

loannis N. Charalampopoulos,

University of Crete, Greece

Olagide Wagner Castro,

Federal University of Alagoas, Brazil

Raghavendra Upadhya,

Texas A\&M Health Science Center,

United States

Abdul R. Asif,

Georg-August-Universität Göttingen,

Germany

*Correspondence:

Sabine Wislet

s.wislet@uliege.be:

s.wislet@ulg.ac.be

Received: 15 February 2018 Accepted: 25 June 2018

Published: 23 August 2018

Citation:

Wislet $S$, Vandervelden $G$ and Rogister B (2018) From Neural Crest Development to Cancer and Vice Versa: How p $75^{\text {NTR }}$ and (Pro)neurotrophins Could Act on

Cell Migration and Invasion?

Front. Mol. Neurosci. 11:244. doi: 10.3389/fnmol.2018.00244
The p75 neurotrophin receptor (p75 NTR), also known as low-affinity nerve growth factor, belongs to the tumor necrosis factor family of receptors. p75 NTR is widely expressed in the nervous system during the development, as well as, in the neural crest population, since $\mathrm{p} 75^{\mathrm{NTR}}$ has been described as ubiquitously expressed and considered as a neural crest marker. Neural crest cells (NCCs) constitute an transient population accurately migrating and invading, with precision, defined sites of the embryo. During migration, NCCs are guided along distinct migratory pathways by specialized molecules present in the extracellular matrix or on the surfaces of those cells. Two main processes direct NCC migration during the development: (1) an epithelial-to-mesenchymal transition and (2) a process known as contact inhibition of locomotion. In adults, p75 NTR remains expressed by NCCs and has been identified in an increasing number of cancer cells. Nonetheless, the regulation of the expression of p $75^{\mathrm{NTR}}$ and the underlying mechanisms in stem cell biology or cancer cells have not yet been sufficiently addressed. The main objective of this review is therefore to analyze elements of our actual knowledge regarding p $75^{\text {NTR }}$ roles during the development (mainly focusing on neural crest development) and see how we can transpose that information from development to cancer (and vice versa) to better understand the link between $\mathrm{p} 75^{\mathrm{NTR}}$ and cell migration and invasion. In this review, we successively analyzed the molecular mechanisms of $p 75^{\mathrm{NTR}}$ when it interacts with several coreceptors and/or effectors. We then analyzed which signaling pathways are the most activated or linked to NCC migration during the development. Regarding cancer, we analyzed the described molecular pathways underlying cancer cell migration when p75 NTR was correlated to cancer cell migration and invasion. From those diverse sources of information, we finally summarized potential molecular mechanisms underlying p75 NTR activation in cell migration and invasion that could lead to new research areas to develop new therapeutic protocols.

Keywords: p75 ${ }^{\text {NTR }}$, neurotrophin, migration, invasion, cadherin, ephrin, kidins220

\section{INTRODUCTION}

The p75 neurotrophin receptor (p75 ${ }^{\mathrm{NTR}}$ ) was first identified in Sutter et al. (1979) and described as a low-affinity nerve growth factor (NGF) receptor. In the early eighties, $\mathrm{p} 75^{\mathrm{NTR}}$ was already described as significantly overexpressed in multiple neural crest-derived cancers such as melanoma or neurofibroma (Ross et al., 1984); however, its role in normal conditions was still undefined 
even if its distribution during the development started to be well characterized. Indeed, in 1990, Heuer and collaborators described the expression of low-affinity NGF receptors in premigratory neural crest cells (NCCs), in epibranchial placode cells, and in all sensory, sympathetic, and parasympathetic derivatives of these structures. In the central nervous system, at the later stage of the development, p $75^{\mathrm{NTR}}$ was detected in a substantial fraction of cells in every brain region, with the highest levels present in developing motor neurons (Heuer et al., 1990). Finally, p75 ${ }^{\text {NTR }}$ was also observed in mesenchymal cell populations including cells in branchial arch, sclerotome, muscle, and feather follicles (Heuer et al., 1990). Baldwin et al. (1992) described the structure of $\mathrm{p} 75^{\mathrm{NTR}}$ containing an extracellular region with four cysteine-rich repeat regions (loops), all of which were required for ligand binding. Since then, more than 10,000 studies have been conducted to understand and characterize the roles of this receptor, in normal and pathological conditions. In 2018, new roles for this receptor are still suggested in cancer cell invasion and migration. Indeed, migration is defined as a process by which a cell goes from one point to another adopting several motility modes, whereas invasion characterizes a cell's ability to become mobile and migrate through a tissue or infiltrate neighboring tissues. Currently, p75 ${ }^{\mathrm{NTR}}$ expression has been correlated to cell migration and invasion in multiple cancer types; however, the molecular pathways underlying $\mathrm{p} 75^{\mathrm{NTR}}$ roles, in those processes, remain unclear. Therefore, the main objective of this review is to analyze all information regarding $\mathrm{p} 75^{\mathrm{NTR}}$ roles in migration and invasion, during the development (mainly focusing on NCCs) and potentially transpose the information to the observations made in cancers (and vice versa). To do so, we will first summarize our actual knowledge regarding $\mathrm{p} 75^{\mathrm{NTR}}$ structure and binding partners with regard to migration and invasion processes. We will then deeply analyze the molecular pathways underlying $\mathrm{p} 75^{\mathrm{NTR}}$ roles in NCC invasion and migration during the development and compare those migration and invasion molecular pathways to the information related to cancer cell migration and invasion. Altogether, this will provide us a clearer view of the main factors regulating $\mathrm{p} 75^{\mathrm{NTR}}$ functions in cell migration and invasion, thereby facilitating the development of new therapeutic strategies in cancer treatments.

\section{STRUCTURE OF P75 NTR AND BINDING PARTNERS}

p $75^{\mathrm{NTR}}$ is a single membrane-spanning protein in the tumor necrosis factor (TNF) receptor family (Heuer et al., 1990). p $75^{\mathrm{NTR}}$ is a 427 -amino-acid transmembrane receptor containing an extracellular domain (ECD) with a cleavable 28 amino acid (aa) signal peptide, followed by four 40 aa extracellular cysteine-rich domains, one of which contains a $\mathrm{N}$-glycosylated site (Figure 1A). Multiple $O$-glycosylation sites exist in the juxtamembrane domain. The intracellular domain (ICD) contains an 80 aa death domain (DD), the signature of the tumor necrosis factor (TNF) receptor family that includes sites for interactions with numerous signaling effectors. The DD is a globular complex protein including six-helix bundle fold.
DD-containing proteins play important roles in inflammatory and in apoptotic signaling through the formation of oligomeric protein complexes (Lin et al., 2015). p $75^{\mathrm{NTR}}$ contains a DD similar, in some ways, to other TNF-associated DDs. However, a major difference between $p 75^{\mathrm{NTR}}$ and other TNF receptors is that the $\mathrm{p} 75^{\mathrm{NTR}} \mathrm{ICD}$ is unable to autoactivate and has to interact with other effector proteins to exert its functions (Meeker and Williams, 2014). Another remarkable specificity of $\mathrm{p} 75^{\mathrm{NTR}}$ (compared to other TNF receptors) is the $29 \mathrm{AA}$ juxtamembrane region, which is also known as the Chopper domain, located at the N-terminal part of the DD. In this case, the Chopper domain has the ability to independently interact with apoptotic peptidase-activating factor 1 (APAF-1) to induce cell death (reviewed by Skeldal et al., 2011; Meeker and Williams, 2014). Altogether and depending on the type of interactions with a specific coreceptor and/or effector, a wide range of signaling events may occur that lead to many different responses (Meeker and Williams, 2014). The most significant identified $\mathrm{p} 75^{\mathrm{NTR}}$ signaling pathways include Ras homolog gene family, member A (RhoA), Jun N-terminal kinase (JNK), mitogen-activated protein kinase (MAPK), and nuclear factor карpa B (NFкB) (Wang et al., 2008). These pathways are possibly activated through various regions of the ICD upon interactions with other proteins (Wang et al., 2008). Among those proteins, guanine nucleotide dissociation inhibitor (Rho-GDI), ribosome-inactivating protein-2 (RIP-2), and $\mathrm{p} 75^{\mathrm{NTR}}$-associated cell death executor (NADE) have been described as interacting with the $\mathrm{p} 75^{\mathrm{NTR}} \mathrm{DD}$ (Wang et al., 2008). Likewise, Schwann cell factor-1 (SC-1), neurotrophin receptor-interacting MAGE homolog (NRAGE), tumor necrosis factor (TNF) receptorassociated factor (TRAF), and neurotrophin receptor-interacting factor (NRIF) have been described as inducing those signaling pathways through interactions with the juxtamembrane region of p $75^{\text {NTR }}$ (Wang et al., 2008). Finally, it was demonstrated that an ankyrin-rich membrane-spanning protein (ARMS) initially identified as Kidins 220 is able to interact with the ICD to form a ternary complex with Trk receptors (Chang et al., 2004).

Beside intracellular effectors, neurotrophins (NTs) play pivotal roles in $\mathrm{p} 75^{\mathrm{NTR}}$ signaling pathways. NTs belong to a large group of growth factors that mainly target neurons of the central and peripheral nervous systems, during the development. NTs are known, among other activities, to stimulate neurite growth, to maintain viability, or to induce cell differentiation. The first NT to be defined was the NGF (Sutter et al., 1979). Historically, it was also the first growth factor to be purified and characterized in 1960 (Aloe, 2004). Several years later, a homolog of the NGF was isolated, characterized, and named brain-derived neurotrophic factor (BDNF) (Barde et al., 1982). Molecular cloning experiments defined two more mammalian members of this family, NTs 3 and 4/5 (NT3 and NT4/5) (Maisonpierre et al., 1991; Ip et al., 1992). NTs activate two different classes of receptor: the tropomyosin-related kinase receptors family (Trk A, B, and C) and the low-affinity-NGF receptor named p $75^{\text {NTR }}$ (Huang and Reichardt, 2001).

Neurotrophins are expressed by the cells as a proneurotrophin (proNT) and are matured by proteolysis processes. When proNTs were initially discovered, they were considered as inactive 
precursors of the mature proteins (reviewed by Meeker and Williams, 2014). However, multiple studies indicated that the proNTs are also physiologically active (Lee et al., 2001) and that NT signaling pathways work through a balance between mature and immature (pro-) NTs (reviewed by Meeker and Williams, 2014). Likewise, it has been suggested that the interactions of p75 ${ }^{\text {NTR }}$ with its coreceptors regulate the availability of highaffinity targets for mature or immature (pro-) NTs (reviewed by Meeker and Williams, 2014).

Neurotrophins can act directly or indirectly on $\mathrm{p} 75^{\mathrm{NTR}}$ mainly through its interactions with three major coreceptor families: Trk (A, B, and C), sortilin, and Nogo receptors (Meeker and Williams, 2014; Figure 1B). Trk receptors were first identified as colon-derived oncogene in which tropomyosin was fused to a tyrosine kinase domain. Currently, three Trk receptors have been identified: TrkA (or NTRK1), TrkB (or NTRK2), and TrkC (or NTRK3). Trk receptors are characterized by the presence of an extracellular domain, with three tandem leucine-rich motifs flanked by two cysteine clusters in their amino termini, and two immunoglobulin-like domains in the membrane-bound region (Huang and Reichardt, 2001). Differential splicings of the TrkA, TrkB, and TrkC mRNAs result in protein expression with various ligand affinities due to changes into their extracellular domain (Huang and Reichardt, 2001). The presence or absence of short amino-acid sequences, in the juxtamembrane domain of each receptor, affects the ability of some NTs to activate these receptors (Huang and Reichardt, 2001). Each Trk has therefore a different NT binding specificity: TrkA binds NGF, TrkB binds BDNF and NT4/5, and TrkC binds NT3 (TrkA and TrkB bind NT3 but to a lesser extent). As reviewed by Pramanik et al. (2016), interactions between Trk receptors and p75 ${ }^{\text {NTR }}$ increase the binding affinity for NTs and support pro-survival and pro-growth signaling via various pathways such as MEK/ERK, PI3K/AKT, and PLC $\gamma$. Regarding migration and invasion (and among other examples), TrkA overexpression has been linked to breast cancer cell migration and invasion through PI3K and ERK/p38 MAP kinase pathways (Lagadec et al., 2009). TrkB overexpression has been shown to induce epithelial-to-mesenchymal transition (EMT), leading to invasion processes of head and neck squamous cell carcinoma (Kupferman et al., 2010). Likewise, BDNF/TrkB have been linked to neuroblastoma cell migration through PI3K/Akt/mTOR and MAPK pathway activations (Hua et al., 2016). TrkC has also been linked to cell migration as TrkC upon NT3 activation leads to adenoid cystic carcinoma cell migration through AKT/ERK pathway activations (Ivanov et al., 2013).

Besides Trk receptors, the most studied non-Trk p $75^{\text {NTR }}$ coreceptor is sortilin. Sortilin, also known as neurotensin receptor 3 (NTS3 or NTR3), belongs to the vacuolar protein sorting 10 (Vps10) domain family (Wilson et al., 2014). Sortilin is a sorting protein mainly found within late endosomes derived from the trans-Golgi network. In this context, sortilin has been described as assisting the anterograde trafficking of NT receptors and to control proBDNF secretion (Reviewed by Meeker and Williams, 2014). With regards to invasion and migration, it has been demonstrated that proNGF induced migration in thyroid cancer cells, through $\mathrm{p} 75^{\mathrm{NTR}} / \mathrm{TrkA} /$ sortilin leading to SRC signaling pathway activation (Faulkner et al., 2018). Likewise, in clear cell renal cell carcinoma, it was shown that proBDNF induced cell migration through $\mathrm{p} 75^{\mathrm{NTR}} / \mathrm{TrkB} /$ sortilin leading to the activation of AKT and ERK pathways (De la Cruz-Morcillo et al., 2016).

The Nogo receptors (NgR1, NgR2, and NgR3) are glycophosphatidylinositol (GPI)-anchored receptors mainly expressed by neurons, in the central and peripheral nervous systems (He et al., 2003). NgRs are cell-surface receptors presenting a highly conserved eight leucine-rich repeats (LRR) flanked by cysteine-rich LRRNT (leucine-rich repeat N-terminal) and LRRCT (leucine-rich repeat C-terminal) domains, as classically described for the LRR family proteins. As described by Saha and collaborators, the LRR domains are connected to the GPI-anchor for membrane attachment via a "stalk" region (Saha et al., 2014). The LINGO-1 receptor is the functional component of NgR. LINGO-1 contains an LRR domain, an immunoglobulinlike domain, a stalk domain, a transmembrane region, and a
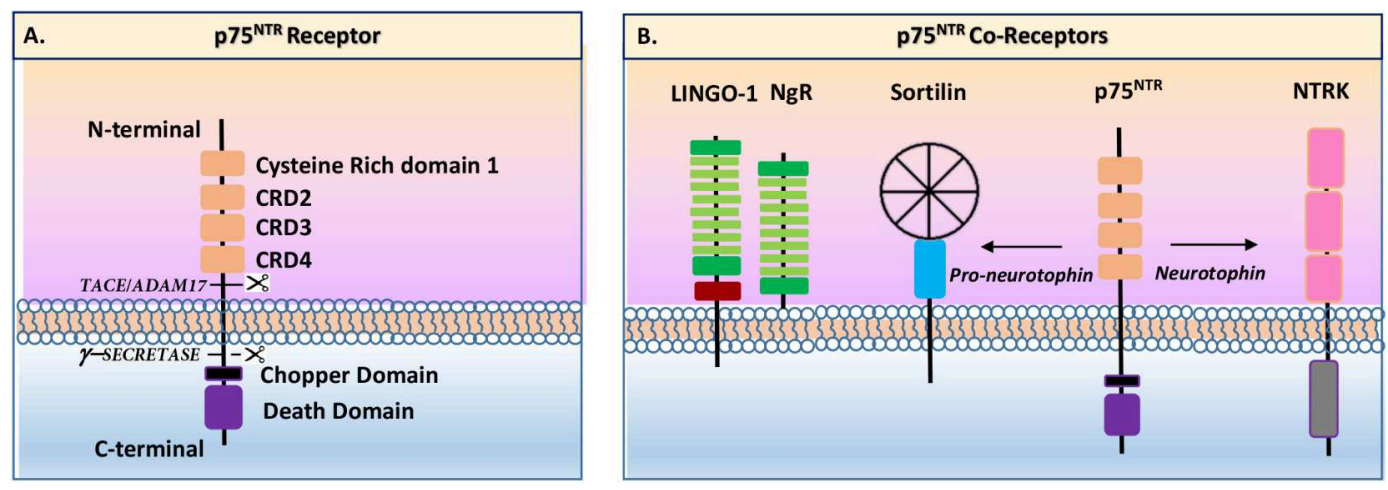

FIGURE 1 | Schematic view of p75NTR receptor and coreceptors (inspired by Skeldal et al., 2011). (A) p75NTR present an extracellular N-terminal part including four cysteine-rich domains (CRD) and a single-peptide transmembrane domain, and an intracellular c-terminal part containing a Chopper domain and a death domain. The extracellular part is cleavable by TACE/ADAM17 enzyme while the intracellular part is cleavable by gamma-secretase enzyme. (B) p75 NTR has several coreceptors including sortilin, TrkA, TrkB, TrkC, and Nogo receptors (NgR). 
short cytoplasmic tail. In the migration context, it seems that Nogo receptors could have inhibitory or inductive effects on cell migration and invasion. Indeed, Jin et al. (2016) demonstrated that Nogo-A was able to inhibit the migration and invasion of human malignant glioma cells via the downregulation of RhoA-cofilin signaling. On the contrary, NgR3 seems to induce nasopharyngeal carcinoma cell migration by activating focal adhesion kinase (FAK) (He et al., 2018).

As the main objective of this review is to understand the role of $\mathrm{p} 75^{\mathrm{NTR}}$ in cell migration and invasion, we will mainly focus the next parts of this review on $\mathrm{p} 75^{\mathrm{NTR}}$ cellular and molecular pathways with regard to those processes.

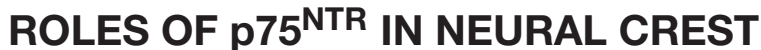 CELL MIGRATION DURING DEVELOPMENT}

The NCCs constitute an transient population accurately moving and undergoing a wide dispersion along multiple pathways, invading with precision defined sites of the embryo and differentiating into many derivatives (Zanin et al., 2013). As reviewed by Vega-Lopez et al. (2017), NCCs are generated along the entire length of the anterior-posterior axis, with the exception of the most anterior part of the embryo. NCCs are guided along distinct migratory pathways by specialized adhesion molecules in the extracellular matrix or by molecules on the surface of the cells, in the embryonic periphery (Vega-Lopez et al., 2017). The NCCs that migrate and invade multiple tissues originate from four different segments of the anterior-posterior axis: cranial, vagal, trunk, and sacral (Vega-Lopez et al., 2017).

The cranial NCCs participate in the formation of most of the craniofacial connective tissues and structures including craniofacial nerves, bones, oral muscles, tongue, the dental pulp and periodontal ligament, pigment cells, the choroid, the optic nerve, and the retina (Vega-Lopez et al., 2017). The cardiac NCC participates in heart development, while the vagal neural crest contributes to the enteric ganglia of the gut (Vega-Lopez et al., 2017). Finally, the trunk neural crest also give rise to neurons and glia of the peripheral nervous system, secretory cells of the endocrine system, and pigment cells of the skin (Vega-Lopez et al., 2017). It has also been described that bone marrow-derived NCCs that participate to the hematopoietic niches are also originating from the trunk neural crest (Coste et al., 2015).

In those NCC populations, $\mathrm{p} 75^{\mathrm{NTR}}$ has been described as ubiquitously expressed and considered as neural crest marker (Pan et al., 2016). However, even if $\mathrm{p} 75^{\mathrm{NTR}}$ expression is widely observed from embryonic to adult stage, its role remains unclear. Based on knockout mice invalidated for the $\mathrm{p} 75^{\mathrm{NTR}}$ gene, we learned that Schwann cell migration from the dorsal root ganglia was significantly decreased in the $\mathrm{p} 75^{-/-}$embryos (Bentley and Lee, 2000). Based on the same knockout mouse model, Wang and collaborators suggested that p75-dependent signaling plays a crucial role in the migration of epidermal Langerhans cells (LC) and in the initiation of cutaneous immune responses (Wang et al., 1997). Since $\mathrm{p} 75^{\mathrm{NTR}}$ is strongly expressed in migrating NCCs,
Kaartinen's team (Bogenmann et al., 2011) generated tissuespecific $\mathrm{p} 75^{\mathrm{NTR}}$ mutants by crossing $\mathrm{p} 75^{\mathrm{NTR}-L O X / L O X}$ mice with transgenic Wnt1-Cre driver mice, which are known to be able to induce a robust recombination in early migratory NCCs (Jiang et al., 2000). According to this study, it appeared that $\mathrm{p} 75^{\mathrm{NTR}}$ was specifically ablated in the dorsal root ganglia, as observed for the full $\mathrm{p} 75^{\mathrm{NTR}} \mathrm{KO}$ mice. In the same study, the authors showed a decrease of $30 \%$ in the sciatic nerve diameter compared to the control littermates (Bogenmann et al., 2011). Likewise, p75 NTR-Lox/lox/Wnt1-Cre mutants presented a hematopoiesis deficiency (Bogenmann et al., 2011) suggesting a dysregulation of the hematopoietic niches with regards to the potential absence of NCCs in bone marrow, in such transgenic mice (Garcia-Garcia et al., 2015).

To understand the potential roles of $p 75^{\mathrm{NTR}}$ in NCC migration, we have to examine further and analyze multiple molecular factors that control NCC migration (Figure 2). During the development, NCCs proceed to an EMT, which includes the loss of tight and adherent junctions, modifications of the apical-basal cell polarity and rearrangements of the cytoskeleton, which will help cells to start migrating (Pegoraro and MonsoroBurq, 2013). During EMT, the transcription factor Twist1 is activated by a variety of signal transduction pathways, including AKT signal transducers (Figures 3A, 4A). Activated Twist-1 upregulates $N$-cadherin and downregulates $E$-cadherin (also known as cadherin-2 and 1, respectively), which are the hallmarks of EMT (Vincentz et al., 2008). Likewise, it has been demonstrated that NCCs are trapped into the neural tube in Twist-1 knockout mice (Vincentz et al., 2008). Twist-1 is also known to induce expression of cell migration markers including periostin, cadherin-11, and MMP2/MMP9 (Shelton and Yutzey, 2008); however, it is unclear if it is through a direct or indirect induction (Kim et al., 2014).

Cadherins are proteins that could behave as ligands as well as receptors and are divided into several categories: (1) type I (classical) including $E$-cadherin (cadherin-1) and type II including $N$-cadherin (cadherin-2), as well as cadherin-11. Type I and II are ultimately linked to the actin cytoskeleton, (2) the desmosomal cadherins (desmocollins and desmogleins), which are linked to intermediate filaments, (3) the protocadherins, which are expressed primarily in the nervous system, and (4) unconventional cadherins including VE-cadherin (cadherin-5), K-cadherin (cadherin-6 present in kidney) and R-cadherin (cadherin-4, present in the retina) (Patel et al., 2003).

Cadherin-11 has been described as an emerging contributor to embryonic development, tissue morphogenesis, as well as tumor invasion and metastasis (Kim et al., 2014). The ectodomain of cadherin-11 leads to homophilic ligation and adhesive recognition, whereas protein interaction with the highly conserved cytoplasmic tails leads to actin cytoskeleton remodeling and cell signaling pathways (Yap and Kovacs, 2003). Cadherin-based cell adhesion activates phosphatidylinositol 3kinase (PI3K) and AKT (Kim et al., 2014, Figure 3A). Likewise, it has been shown that cadherin-11 interacts with ErbB2 receptor to activate AKT pathway and NCC migration (Mathavan et al., 2017). 


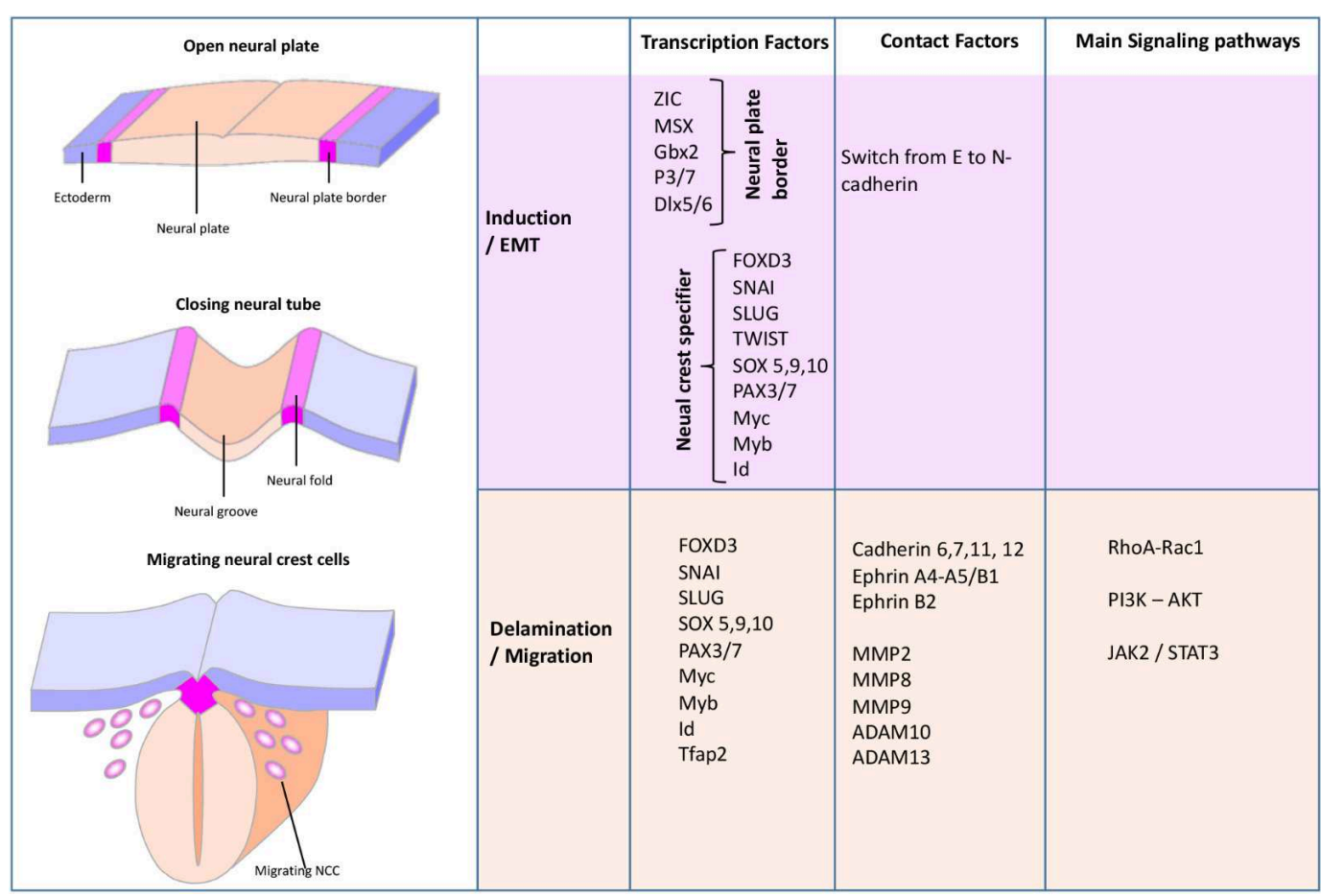

FIGURE 2 | Schematic view of the neural crest formation and migration during the early steps of the development (Glejzer et al., 2011). During the NCC development, several transcription factors, contact factors, as well as signaling pathways orchestrate NCC EMT, invasion, and migration.

According to a recent study, cadherin 6 (type-2), 7 (type-2), and 12 (N-cadherin-2) are also upregulated during NCC migration, whereas cadherin-5 (VE-cadherin) and 10 (type-2) are downregulated (Morrison et al., 2017). Cadherin-6 has been suggested to promote EMT by mediating proEMT signals (Clay and Halloran, 2014). Moreover, cadherin-6 knockdown in NCC alters the subcellular distribution of active Rho, which is known to promote localized actomyosin contraction, a crucial step for apical NCC detachment (Clay and Halloran, 2014). Another study demonstrated that cadherin-7 is upregulated in migrating NCCs in response to ectopic Wnt activation (Prasad and Paulson, 2011). Likewise, Fujita et al. (2016) demonstrated that cadherin-7 directly induces FoxD3 expression when stimulated by BMP2/Wnt3a signaling and plays important roles in this process of NCC formation. The molecular pathways and the exact roles of cadherin-5, cadherin-10, and cadherin-12 during NCC migration have not been investigated so far.

Another aspect of NCC migration concerns cell collision. Collision between cells can cause them to move away from each other, a process known as contact inhibition of locomotion (CIL). CIL is required for NCC migration. As described by Smeets et al. (2016), CIL leads to regular cell arrangements and hinders the formation of cohesive tissues. CIL is a complex process that involves many different molecular mechanisms. As reviewed by Roycroft and Mayor (2016), the CIL processes can be divided into four different stages:

(1) initial contact between the cells

(2) inhibition of protrusive activity at the site of contact
(3) cell repolarization and formation of new protrusions away from the contact

(4) cell separation and migration away from each other.

Each of the four distinct steps of CIL requires changes to the cytoskeleton driven by a variety of molecular components via the recruitment of regulatory factors such as the cell polarity protein Par3 (also known as Pard3) (Moore et al., 2013; Roycroft and Mayor, 2016).

Par3 has been described as a driver for the maturation of the cell adhesion complex and has been linked to the regulation of microtubule dynamics and Racl activity through interaction with the Rac-GEF Tiam-1 (Moore et al., 2013, Figure 3A). Likewise, it has been shown that Par3 controls CIL by inhibiting the RacGEF Trio to prevent Trio-mediated activation of Racl at cell-cell contacts (Moore et al., 2013, Figure 3A). Nonetheless, Moore and collaborators suggested that cadherin 11 act as a regulator of Par3 functions at the cell contact as it has been shown that during NCC migration, the Rac-GEF Trio interact with cadherin 11, which is localized to cell protrusions as well as cell-cell contacts (Moore et al., 2013, Figure 3A). The link between Par3 and $p 75^{\mathrm{NTR}}$ has not been established during NCC migration; however, it has been demonstrated that in Schwann cell myelination, BDNF activates Par3 through $\mathrm{p} 75^{\mathrm{NTR}}$ interaction in order to induce Rac1 (Tep et al., 2012, Figure 3A).

Besides Par3, the switch from $E$ to $N$-cadherin, as well as from ephrin A to ephrin B are essential for CIL between NCCs (Roycroft and Mayor, 2016). Again cadherin-11 is implicated in CIL since Becker et al. (2013) demonstrated that cadherin-11 

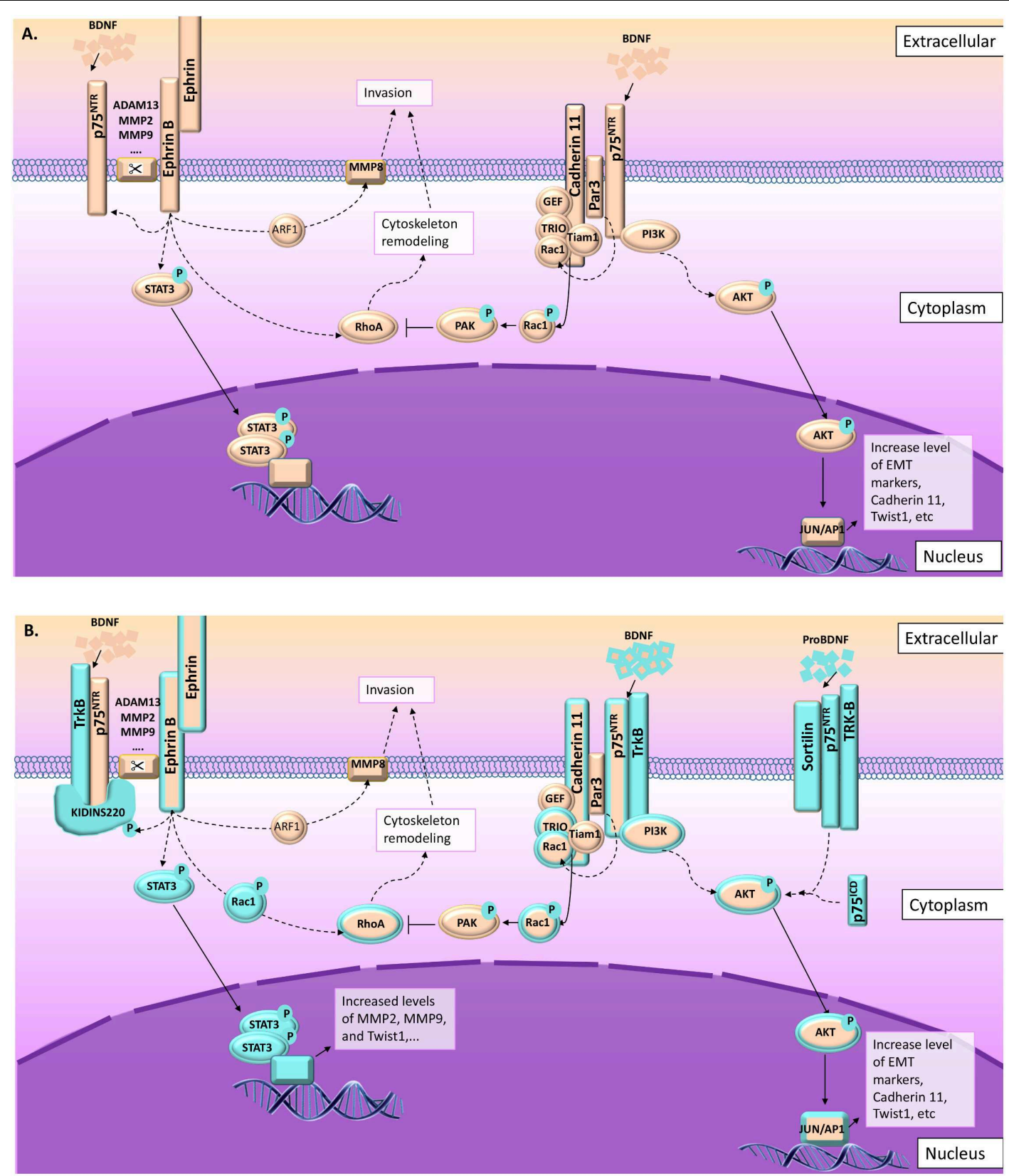

FIGURE 3 | p75 NTR and TrkB pathways leading to migration and invasion in normal and pathological conditions. As described in this figure, several signal pathways are preferentially activated in cell invasion and migration processes involving p $75^{\mathrm{NTR}}$ upon NT activation. From the left to the right: (1) ephrin-B receptor phosphorylate Kidins220/ARMS leading to $\mathrm{p} 75^{\mathrm{NTR}} / \mathrm{TrkB}$ activation (Neubrand et al., 2012; Cai et al., 2017) and increasing their sensitivity to BDNF, leading to the activation of MAPkinase signaling pathways (Liao et al., 2011). Ephrin-B receptor activation is also linked to STAT3 and RhoA signaling leading to cytoskeleton remodeling (Marler et al., 2010; Neubrand et al., 2012). (2) In the absence of Kidins220/ARMS, p75 NTR/TrkB could interact with other scaffold proteins like Par3 (Moore et al., 2013; Gomez et al., 2018). In this context, the BDNF activates p75NTR/TrkB leading to AKT pathway activation, but also to Par3 activation (Gomez et al., 2018). Activated Par3 activates Rac1, which modifies cadherin-11 interaction with catenins leading to cytoskeleton remodeling (Moore et al., 2013). (3) In some cases, $\mathrm{p} 75^{\mathrm{NTR}} / \mathrm{TrkB}$ also interact with sortilin leading to a high sensitivity to proBDNF. ProBDNF/p75 NTR $/$ TrkB also activate AKT pathway (De la Cruz-Morcillo et al., 2016). (A) Information collected from NCC migration and invasion during the development. (B) Information collected from cancer studies (highlighted in blue). Orange and blue borders = information related to both situations, NCC and cancer cells migration and invasion.

mediated cell-cell adhesion was necessary in CIL for directional and collective NCC migration through Racl and small RhoGTPase RhoA signaling. Indeed, Rho-GTPases play active roles in remodeling the actin cytoskeleton and in the regulation of microtubules (Roycroft and Mayor, 2016). Interestingly, it has been demonstrated that the DD of $\mathrm{p} 75^{\mathrm{NTR}}$ is able to interact with Rho-GDI for the activation of RhoA pathway (Lin et al., 2015, Figure 3A). 

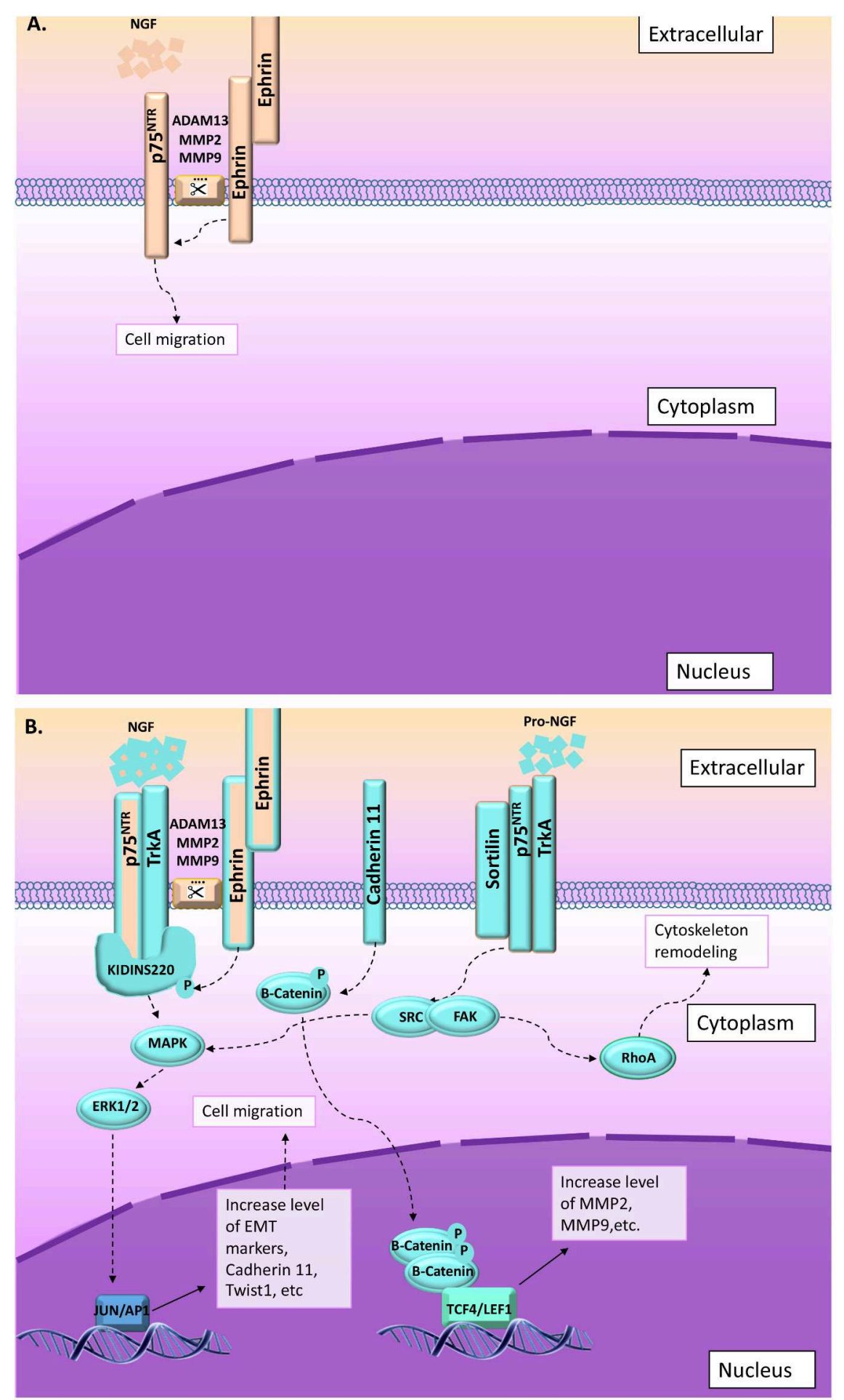

FIGURE 4 | In some cases, migration and invasion are stimulated through NGF or proNGF upon activation of p75 NTR and TrkA. Two main pathways are described in that context: (1) ephrin-B receptor activated through interaction with ephrin-ligand (from surrounding cells) phosphorylate Kidins220/ARMS leading to increase p75 NTR/TrkA affinity for NGF (Liao et al., 2011; Schmieg et al., 2015; Restivo et al., 2017). Upon NGF activation, p75 NTR/TrkA/Kidins220/ARMS activate MAPkinase pathway (Liao et al., 2011). (2) Migration and invasion is also activated through proNGF/sortilin/p75 NTR/TrkA (Faulkner et al., 2018). In this context, SRC/RhoA signaling pathway is activated leading to cytoskeleton remodeling (Faulkner et al., 2018). (A) Information collected from NCC migration and invasion during the development. (B) Information collected from cancer studies (highlighted in blue). Orange and blue borders = information related to both situations, NCC and cancer cells migration and invasion. 
Ephrins are membrane-bound proteins that mediate bidirectional signals between adjacent cells (Baker and Antin, 2003). Ephrins are known to direct cell movements during multiple morphogenetic processes, including NCC migration, through cytoskeleton remodeling processes (Baker and Antin, 2003). Ephrin receptors and ephrin ligands are subdivided into two subclasses with distinct binding specificities that correlate with structural similarities: Ephrin-A ligands (named ephrin-A1 to ephrin-A5) are anchored in the plasma membrane through a GPI-linkage, and each of them can bind any of the ephrinA subclass of receptors (ephrin-A1 to ephrin-A8) (O'Leary and Wilkinson, 1999). On the other hand, ephrin-B ligands (ephrin-B1 to ephrin-B3) have a transmembrane domain and a cytoplasmic region and are able to interact with members of the ephrin-B subclass of receptors (ephrin-B1-ephrin-B6) as well as to the ephrin-A4 receptor (O'Leary and Wilkinson, 1999).

As reviewed by Theveneau and Mayor (2012), migratory NCCs and their surrounding tissues express a wide variety of ephrins. Indeed, ephrin signaling takes place in three different situations:

(1) NCCs belonging to different streams express different genetic repertoires, preventing them from mixing and keeping the streams separated (Theveneau and Mayor, 2012).

(2) NCCs are prevented from invading areas where non-NCCs express complementary ephrins (Theveneau and Mayor, 2012).

(3) NCCs and their invaded tissues may display matching receptor and ligand codes to allow homing (Theveneau and Mayor, 2012).

Ephrin-A4 and ephrin-A5 have been described as downregulated during early NCC migration, whereas ephrinB1 was upregulated (Morrison et al., 2017). Ephrin-B1 has been reported to interact with the signal transducer and activator of transcription 3 (STAT3), in a phosphorylationdependent manner that leads to enhanced activation of STAT3 transcriptional activity (Bong et al., 2007, Figure 3A). Moreover, it was demonstrated that STAT3 activity, in this context, depended on the tyrosine kinase Jak2, and two tyrosines within the ICD of ephrin-B1 that were critical for its association with STAT3 and its activation (Bong et al., 2007).

A closer look to ephrin receptors and ligands indicated that their interactions occur between adjacent cells mediating juxtacrine signaling (Atapattu et al., 2014). Ephrin receptor and ligand interactions involve clusters of receptors and ligands leading to large receptor-ligand complexes, also including cadherins (Atapattu et al., 2014). Ephrin activation requires proteolytic cleavage that is processed by a variety of proteases including a disintegrin and metalloproteases (ADAMs) (Atapattu et al., 2014, Figures 3A, 4A). ADAM13 has been reported to specifically cleave ephrin-B ligands as well as other proteins including cadherin-11 and is linked to NCC migration during the development (Gaultier et al., 2002). In this context, it appears that ADAM13 is able to upregulate canonical Wnt signaling and early expression of the transcription factor snail2, whereas ephrin-B inhibits this pathway, suggesting a role of ephrin-B cleavage by ADAM13 in the repression of canonical Wnt signaling (Wei et al., 2010).
Similar to ADAM proteases, matrix metalloproteases (MMP) have been reported to cleave ephrin ligands and receptors. MMPs are classically described for their ability to degrade extracellular matrix components to facilitate cell migration; however, they also participate in the proteolysis of several growth factors and receptors like FGFR or ErbB receptors (Peschon et al., 1998). Looking at cell migration and invasion, it has been reported that ephrin-B2 receptor which is activated upon ephrin-B1 ligand interaction and MMP8 cleavage, activate Arf1 and RhoA allowing their interacting with Disheveled and leading to cell repulsion and invasion (Lin et al., 2008, Figure 3A). Likewise, MMP2/MMP9 have been described as activating ephrin-B4 receptor/ephrin-B2 ligand and mediate migration of endothelial cells via PI3Kinase/AKT pathway (Steinle et al., 2002). As mentioned above, Twist-1 is a regulator of MMP2/MMP9 expression leading to early NCC migration, during the development (Figure 3A).

Regarding $\mathrm{p} 75^{\mathrm{NTR}}$ interactions with ephrins, it has been shown that the BDNF induced ephrin-A5 ligand/eprhin-B2 receptor/p $75^{\mathrm{NTR}}$ interactions leading to cytoskeleton remodeling (Marler et al., 2010, Figure 3A). Another interesting link between $\mathrm{p} 75^{\mathrm{NTR}}$ and ephrin receptors and/or ligands has been established several years ago as kinase D-interacting substrate of $220 \mathrm{kDa} /$ ankyrin repeat-rich membrane spanning (Kidins220/ARMS), a scaffold protein complex, has been described as interacting with $\mathrm{p} 75^{\mathrm{NTR}}$ as well as other receptors, including ephrin receptors (Neubrand et al., 2012). Most importantly, it was shown that Kidins220/ARMS was activated by phosphorylation after treatment with NGF (Figure 4A), BDNF (Figure 3A), and ephrin-B2, suggesting a critical link between cell surface receptors and intracellular signaling events for both the NT and the ephrin families (Kong et al., 2001). However, the link between NT, p75 ${ }^{\mathrm{NTR}}$, and ephrin in migrating NCCs has not been described so far.

Altogether, it appears that during NCC invasion and migration, $\mathrm{p} 75^{\mathrm{NTR}}$ may play several roles in EMT and CIL events through several pathways including AKT, Rho-GTPase RhoA, and Jak2/STAT3. These signaling pathways seem to be mainly activated through interactions with ephrin and cadherin family members as summarized in Figures 3A, 4A, and could modulate NT effects through $\mathrm{p} 75^{\mathrm{NTR}}$ and potentially coreceptors as well as through scaffold proteins. However, even if ephrin, cadherin, along with $\mathrm{p} 75^{\mathrm{NTR}}, \mathrm{BDNF}$, and NGF have been implicated in NCC migration and invasion during the development, it is still unclear which coreceptors and/or effectors are involved in such processes. To better understand and "fill the gaps," we will now analyze our actual knowledge about $\mathrm{p} 75^{\mathrm{NTR}}$ roles in cancer cell migration and invasion.

\section{ROLES OF $\mathrm{p} 75^{\mathrm{NTR}}$ IN CANCER CELL MIGRATION AND INVASION}

Cancer stem cells (CSCs), also known as tumor-initiating cells, represent a minority population of tumor cells that share the biological characteristics of normal stem cells such as self-renewal and differentiation (Suraneni and Badeaux, 2013). Moreover, 

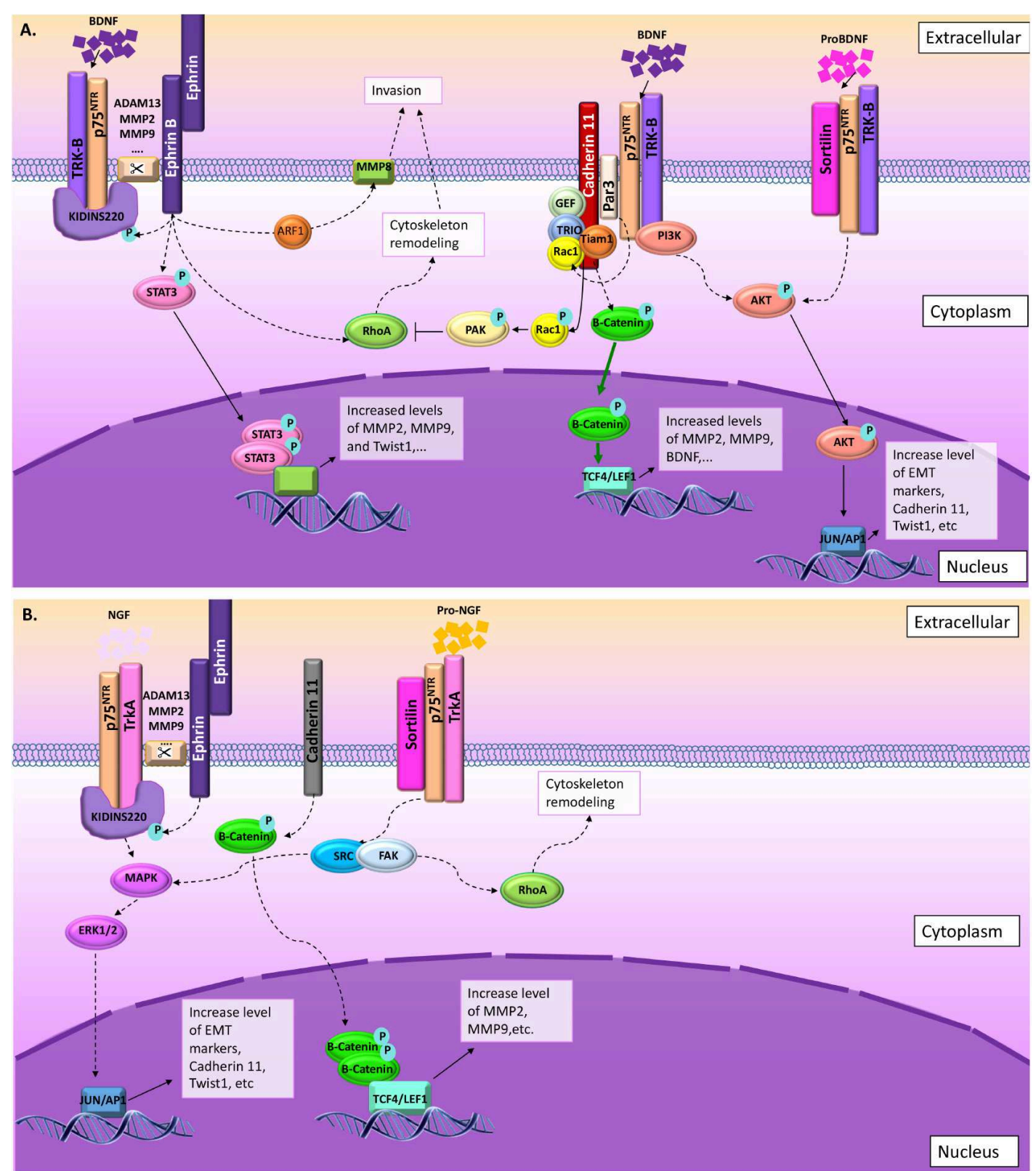

FIGURE 5 | Summary of the signaling pathways involved in cell migration and invasion through p $75^{\mathrm{NTR}}$. (A) BDNF NT may act through p75 following ephrin receptor interaction and phosphorylation or through $\mathrm{p} 75^{\mathrm{NTR}} / \mathrm{TrkB} / \mathrm{Par} 3$ following cadherin interactions. In some rare cases, proBDNF may also

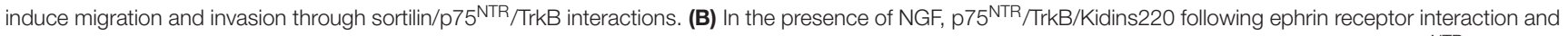
phosphorylation induce MAPK/ERK signaling pathway. Again, in some rare cases, proNGF may also induce migration and invasion through sortilin/p75NTR/TrkA interactions leading to SRC/FAK activation.

CSCs are described as resistant to conventional therapies and are thought to be responsible for recurrence as a driving force for tumor initiation, recurrences, or metastasis. Their identification is functional or operational as they are the only tumor cells able to start a tumor in a xenograft procedure and they are able to grow as spheres when cultivated. Indeed, at least so far, there is no specific marker to identify CSCs.

As mentioned above, during the development, NCCs proceed to an EMT that includes Twist-1 activation leading to the switch from $E$ to $N$-cadherin (Pegoraro and Monsoro-Burq, 2013). These changes are highly similar to those observed in metastatic tumor cells undergoing EMT (Pegoraro and Monsoro-Burq, 2013), as well as in circulating tumoral cells (CTCs) (Lombard et al., 2015). In several cancers, Twist-1 has been identified as a master regulator of EMT (Firulli and Conway, 2008) and is characterized by a downregulation of E-cadherin and an upregulation of $N$-cadherin on cell surfaces (Cho et al., 2016). Twist-1 plays an important role in some physiological processes 
involved in metastasis. In addition, Twist-1 has been described as being responsible for the maintenance of CSCs, the development of chemotherapy resistance (Khan et al., 2013), and in some instances, the radiotherapy resistance (Xiong et al., 2017). In this context, STAT3 signaling pathway seems to be the most common pathway that targets genes like MMP-2, MMP-9, VEGF, and Twist1, which are involved in cell migration and invasion (Cao et al., 2016, Figure 3B).

Another remarkable common point with NCC migration and invasion during development is the fact that cadherin-11 has also been reported to be overexpressed in several cancers and linked to cell migration and invasion (Figures 3B, 4B). Indeed, Birtolo et al. (2017) demonstrated that the knockdown of cadherin-11, in cancer cells, reduced pancreatic cancer cell migration. Likewise, Satcher et al. (2015) showed that clatherinmediated internalization of cadherin-11 regulated the surface trafficking of cadherin-11 and that the dynamic turnover of cadherin-11 regulated the migratory function of cadherin-11, in prostate cancer cells. It was also suggested that $\mathrm{p} 75^{\mathrm{NTR}}$ could impact U87 glioblastoma cell migration through modulation of specific genes, including cadherin-11 (Berghoff et al., 2015). Finally, Li et al.'s (2011) study revealed a novel cadherin-11Trio-Rac signaling axis that contributes significantly to breast cancer cell migration (Figure 3B). As mentioned above, during NCC migration, cadherin-11 modulate the Par3 function that has been linked to the regulation of microtubule dynamics by inhibiting the Rac-GEF-Trio to prevent Trio-mediated activation of Rac1. Likewise, the BDNF has been shown to activate Par3 through its interaction with $\mathrm{p} 75^{\mathrm{NTR}}$. In cancer, studies that performed genome-wide screening for microdeletions revealed that the region containing the Par3 gene was deleted in lung, head and neck, and esophageal squamous cell carcinoma cell lines (Nakamura et al., 2016). In those cancers, Par3 seems to act as a tumor suppressor. Likewise, Par3 has been described as a metastasis inhibitor in pancreatic and breast cancer; however, it has also been shown that in those two cases that Par3 presents an alternative splicing, which could change its interaction capacities with target factors including Rac1 (Ke et al., 2018). On the other hand, in clear cell renal carcinoma, Par3 overexpression was associated with poor prognosis (Nakamura et al., 2016). Likewise, in skin cancer, Par3 acts as a tumor suppressor or a tumor promoter depending on the tumor type; in keratoacanthoma it acts as a tumor suppressor, whereas it acts as a tumor promotor for melanoma (Nakamura et al., 2016). Interestingly, abnormal NT signaling has been implicated in the progression of numerous cancers, including neuroblastoma, medulloblastoma, melanoma, papillary thyroid carcinoma, pancreatic cancer, prostate cancer, and breast cancer (Molloy et al., 2011). Indeed, in lung cancer (Gomez et al., 2018), head and neck cancer (Jiang et al., 2017), and esophageal squamous cell carcinoma (Gomez et al., 2018), BDNF/TrkB/PI3K-AKT seem to be activated and linked to invasiveness (Figure 3B). As mentioned above, BDNF/p75 NTR/PI3K-AKT activate Par3 blocking the Par3 effect (as a negative regulator) on RhoA pathway leading to cytoskeleton remodeling and therefore inducing invasiveness. In clear cell renal carcinoma, it has been shown that invasiveness is independent of BDNF/TrkB signaling, but dependent on the high expression level of $\mathrm{p} 75^{\mathrm{NTR}}$ working through proBDNF activation (De la Cruz-Morcillo et al., 2016, Figure 3B). So far, the link between proBDNF and Par3 has not been established; however, it is possible that proBDNF may indirectly act on Par3 leading to an opposite effect to the one described for the BDNF, similar to what we observed for $\mathrm{p} 75^{\mathrm{NTR}}$. Likewise, it was also shown that proBDNF induced cell migration through $\mathrm{p} 75^{\mathrm{NTR}} / \mathrm{TrkB} /$ sortilin leading to the activation of AKT and ERK pathways (De la CruzMorcillo et al., 2016, Figure 3A). In melanoma, a recent study characterized the interaction of $\mathrm{NGF} / \mathrm{p} 75^{\mathrm{NTR}} / \mathrm{TrkA}$ signaling as a regulator of phenotype switching in melanoma (Restivo et al., 2017, Figure 4B). In this study, the authors described $\mathrm{p} 75^{\mathrm{NTR}}$ as a key effector to drive the melanoma cells to become highly invasive (Restivo et al., 2017). Likewise, in thyroid cancer cells, proNGF works through $\mathrm{p} 75^{\mathrm{NTR}} / \mathrm{TrkA} /$ sortilin leading to SRC signaling pathway activation and cell invasion (Faulkner et al., 2018, Figure 4B).

Beside Par3, other CIL contributors are also necessary for cancer progression. Indeed, it has been described that ephrin$\mathrm{B}$ signaling gives rise to CIL in carcinoma cell lines and can induce high levels of CIL behavior (Roycroft and Mayor, 2016). Likewise, it was demonstrated that ephrin-B4 receptor signaling contributes to the high migratory ability of invasive melanoma cells by influencing RhoA-mediated actin cytoskeleton reorganization (Yang et al., 2006, Figure 3B). Similarly, ephrinB2 and ephrin-B3 expression and phosphorylation correlated with increasing tumor grade and its signaling through Racl was critically important to glioma invasion (Nakada et al., 2006, 2010, Figure 3B).

Currently, the molecular pathways underlying the role of p $75^{\mathrm{NTR}}$ in cancer cell migration and invasion is not fully understood; however, multiple clues in several cancers linked $\mathrm{p} 75^{\mathrm{NTR}}$ to tumor cell migration and invasion. Indeed, proBDNF has been described as inducing renal cell carcinoma cell survival and migration, through $\mathrm{p} 75^{\mathrm{NTR}}$ (De la Cruz-Morcillo et al., 2016). In the same line, proNGF is associated with the invasion and migration of melanoma cells through a mechanism involving p $75^{\text {NTR }}$ and sortilin (Truzzi et al., 2008). Likewise, Shonukan et al. (2003) showed that the activation of p75 $5^{\mathrm{NTR}}$ with NGF or proNGF induced melanoma cell migration and increased the level of expression of $\mathrm{p} 75^{\mathrm{NTR}}$ (Shonukan et al., 2003). Moreover, the effects of NGF and proNGF through $\mathrm{p} 75^{\mathrm{NTR}}$ were correlated with the late stages and the invasive potential of melanoma brain metastasis (Shonukan et al., 2003, Figure 4B).

$\mathrm{p} 75^{\mathrm{NTR}}$ was also correlated with a poor prognosis in human hypopharyngeal cancer (HPC) as Mochizuki and collaborators indicated that $\mathrm{p} 75^{\mathrm{NTR}}$ initiated tumor formation by the activation of Erk-signaling leading to an acceleration of the migration signaling pathway (Mochizuki et al., 2016, Figure 4B). Likewise, in esophageal squamous cell carcinoma, $\mathrm{p} 75^{\mathrm{NTR}}$ overexpression and PI3K/AKT signaling pathway activation induced invasion and migration (Xi et al., 2016, Figure 3B). Likewise, Gomez et al. (2018) demonstrated that in esophageal squamous cell carcinoma, invasiveness was linked to BDNF/TrkB/PI3K-AKT (Figure 3B).

In glioma, several cell lines characterized as brain tumorinitiating cells (BTIC) have been established by culturing cells 
derived from patient tumors. Using those cell lines, several studies demonstrated that the NGF stimulates BTIC proliferation through a $\mathrm{p} 75^{\mathrm{NTR}}$ cleavage. Interestingly, ectopic expression of $\mathrm{p} 75^{\mathrm{NTR}-\mathrm{ICD}}$ was sufficient by itself to stimulate BTIC cell invasion and proliferation (reviewed by Chopin et al., 2016). Moreover, p75 $5^{\mathrm{NTR}-\mathrm{ICD}}$ was able to induce AKT activation in BTIC (Forsyth et al., 2014). Likewise, Berghoff and collaborators also indicated that $\mathrm{p} 75^{\mathrm{NTR}}$ undergoes a $\gamma$-secretase-mediated regulated intramembrane proteolysis and was involved in glioblastoma cell migration and invasion (Berghoff et al., 2015). More recently, Alshehri and collaborators indicated that $\mathrm{p} 75^{\mathrm{NTR}}$ was a central regulator of glioma invasion (Alshehri et al., 2017). These observations correlate with a study indicating that PDLIM1, a novel signaling adaptor for $\mathrm{p} 75^{\mathrm{NTR}}$, was shown to interact with $\mathrm{p} 75^{\mathrm{NTR}}$ in highly invasive patient-derived glioma stem cells/tumor-initiating cells (Ahn et al., 2016). Moreover, silencing PDLIM1 (a member of the PDZ and LIM protein family) in vitro and in vivo resulted in a complete ablation of p $75^{\mathrm{NTR}}$-mediated invasion (Ahn et al., 2016).

In medulloblastoma ( $\mathrm{MB})$, the most aggressive brain tumor in children, it has been reported that $\mathrm{p} 75^{\mathrm{NTR}}$ expression is correlated with cell invasion and migration (Wang et al., 2015). Indeed, in human MB cell lines, $\mathrm{p} 75^{\mathrm{NTR}}$ was shed by $\alpha$-secretase first to generate ECD and the carboxy-terminal fragment, which was still anchored in the membrane, was then cleaved by $\gamma$-secretase to generate an ICD. This $\mathrm{p} 75^{\mathrm{NTR}}$ proteolytic processing was required for $\mathrm{p} 75^{\mathrm{NTR}}$-mediated $\mathrm{MB}$ invasion in vitro and in vivo (Wang et al., 2015, Figure 3B).

All these cancer studies revealed a strong implication of p $75^{\mathrm{NTR}}$ in cell migration and invasion that seems to be induced through multiple pathways. This observation is reinforced by the fact that besides NTs and coreceptors that have been linked to migration and invasions, other effectors may also induce cell migration and invasion through $\mathrm{p} 75^{\mathrm{NTR}}$. In fact, cell migration and invasion have also been reported to be activated by $\mathrm{p} 75^{\mathrm{NTR}}$ through a protein scaffold like Kidins 220 or a $\mathrm{p} 75^{\mathrm{NTR}}$ modulator like NRAGE.

Currently, there is growing evidence showing the involvement of Kidins220/ARMS in various cancers (Raza et al., 2017). As mentioned above, Kidins220/ARMS is a multifunctional transmembrane scaffold protein involved in the regulation of many cellular functions. The most significant role identified for Kidins220/ARMS is as a downstream substrate of NT receptors (Cai et al., 2017). Kidins220 appeared to be phosphorylated following exposure to ephrin-B, suggesting a role downstream of ephrin receptors (Cai et al., 2017). Kidins220/ARMS has also been reported to mediate melanoma cell migration and invasion through activation of ERK/MEK signaling pathways (Liao et al., 2011, Figure 4B). Moreover, the NGF and the BDNF have been shown to modulate the Kidins220/ARMS expression level (Schmieg et al., 2015) and its overexpression drastically induced TrkA expression (Schmieg et al., 2015). As mentioned above, TrkA and $\mathrm{p} 75^{\mathrm{NTR}}$ overexpression have been linked to migration of several cancer cells like in thyroid cancer (Faulkner et al., 2018) or in pancreatic cancers (Bapat et al., 2016). As Kidins220/ARMS is also able to interact with TrkB and TrkC, it is possible that Kidins220/ARMS overexpression could also modulate the TrkB and TrkC level of expression depending on the type of NT induction; however, it has not been investigated so far (Figure 3B).

Similarly to Kidins220/ARMS, numerous efforts have been made to dissect the relationship between NRAGE and tumorigenesis (Zhang et al., 2016). NRAGE also known as MAGE-D1 or Dlxin-1 plays crucial roles in regulating tumorigenesis and metastasis, as its downregulation is associated with metastasis formation in a variety of tumor cells including pancreatic cancer, low-grade gastric cancer, and ovarian cancer (Zhang et al., 2016). NRAGE is known to inhibit cell migration through its interaction with $E$-cadherin. Indeed, $E$-cadherin is known as a cell-cell adhesion molecule that inhibits motility through its interactions with $\alpha$-catenin, $\beta$-catenin, and p120catenin as well as with ankyrin-G (Cai et al., 2014). The $\alpha$-catenin and $\beta$-catenin link also the actin filaments of the cytoskeleton. When the interactions between $E$-cadherin and catenin are broken, $\beta$-catenin is released in its phosphorylated state. Phosphorylated $\beta$-catenin is then transferred from the cytoplasm into the nucleus, where it interacts with transcription factors. Ankyrin-G is known to interact with the cytoskeleton through spectrin and actin complexes and with the plasma membrane, through diverse transmembrane proteins including $E$-cadherin (Frisch et al., 2013). Ankyrin-G has also been shown to sequester NRAGE in the cytoplasm (Kumar et al., 2011). In the absence of ankyrin-G (i.e., after the loss of E-cadherin following EMT), a fraction of NRAGE translocates to the nucleus, where it has been shown to interact with the oncogenic transcriptional repressor protein TBX2 (Kumar et al., 2011). TBX2 has been described as a strong inducer of EMT leading to tumor progression from non-invasive to invasive malignant states (Wang et al., 2012).

So far, NRAGE overexpression has been described as playing a role in migration and invasion of breast cancer (Wang et al., 2012), hepatocellular carcinoma (Shimizu et al., 2016), and highgrade gastric cancer (Kanda and Kodera, 2016). As previously mentioned, in breast cancer, cell migration and invasion are linked to TrkA/ERK/p38 MAP kinase pathways (Lagadec et al., 2009, Figure 4B). Likewise, cadherin-11/p75 NTR/Rho-A and Par3 alternative splicing seem to be also implicated in breast cancer migration and invasion (Figure 3B). On the other hand, in gastric cancer, $\mathrm{p} 75^{\mathrm{NTR}}$ has been reported to inhibit the invasive and metastatic abilities of low-grade cancer cells by suppressing the NFkappaB signal transduction pathway potentially through p75ICD and NRAGE interaction (Jin et al., 2007). However, in highgrade gastric cancer, cellular migration and invasion are mediated through EZH2, COX-2, MCL-1, and FOS genes. Interestingly, EZH2 (the polycomb repressor complex 2 molecule) is known to interact with the TrkA promotor and modulate TrkA silencing (Li et al., 2018).

Finally, it appears that the level of expression of $\mathrm{p} 75^{\mathrm{NTR}}$ would have different effects depending on the cell types. On one hand, its overexpression seems to induce apoptosis in colorectal cancer (Yang et al., 2014) and block the cellular cycle in liver cancer (Yuanlong et al., 2008). On the other hand, p75 NTR promotes survival in breast cancer or metastasis formation and cell invasion in glioma and melanoma (reviewed by Chopin et al., 2016). Interestingly, all cancers in which p $75^{\mathrm{NTR}}$ appears 
to have a repressive effect come from the mesoderm or the endoderm (Chopin et al., 2016). On the contrary, the effects linked to a poorer vital prognosis through an increase rate of metastatic formation, invasion, and migration are observed in cell types arising from the (neur)ectoderm (Chopin et al., 2016). This apparent simple observation is actually even more complicated than suggested above since in low-grade glioma, p75 ${ }^{\text {NTR }}$ and Trk coreceptors have been reported to inhibit tumor growth and survival, whereas the opposite effects were reported in high-grade gliomas (Alshehri et al., 2017). In low-grade gliomas, it appears that the glial cell-derived neurotrophic factor (GDNF) promotes cell migration through JNK, ERK-1/2, and p38 MAPK signaling pathways (Song and Moon, 2006). Likewise, the levels of expression of the NGF and its high-affinity receptor (TrkA) have been shown to be reduced in low-grade gliomas, whereas that of p75 NTR was increased (Chiaretti et al., 2004). In high-grade gliomas, Xiong and collaborators demonstrated that the BDNF promoted cell migration and invasion through TrkB and $\mathrm{p} 75^{\mathrm{NTR}}$, whereas proBDNF had the opposite effects (Xiong et al., 2013). Similar observations were made for other cancers as an increased level of TrkB and BDNF as well as the downregulation of expression of E-cadherin were correlated with the invasion and metastasis of salivary adenoid cystic carcinoma cells (Jia et al., 2015). In gastric cancer, p $75^{\mathrm{NTR}}$ has been reported to inhibit the invasive and metastatic abilities of cancer cells in correlation with the downregulation of metalloprotease-9 (MMP9) proteins and upregulation of the tissue inhibitor of matrix metalloprotease-1 (TIMP1) protein by suppressing the NFkappaB signal transduction pathway (Jin et al., 2007).

All of those observations suggest that $\mathrm{p} 75^{\mathrm{NTR}}$ effects seem to be independent on the cell type, but those effects are rather modulated by the type and the level expression of the specific coreceptor (Trk, sortilin, and Nogo/LINGO) or effector (Par3, Kidins220 scaffold proteins, NRAGE modulator, ephrin, and cadherin) as well as a fine balance between NT and proNT. All these receptors/effectors are able to modulate the signaling pathways induced by extracellular factors including NTs, leading to an array of roles that could be finely tuned.

\section{CONCLUSION}

Looking specifically at the implication of $\mathrm{p} 75^{\mathrm{NTR}}$ in cell migration and invasion in normal and pathological conditions, it appears that two main pathways seem to be mainly activated: (1) $\mathrm{BDNF} / \mathrm{p} 75^{\mathrm{NTR}} / \operatorname{TrkB}$ (Figure 5A) and (2) NGF/p75 ${ }^{\mathrm{NTR}} / \operatorname{TrkA}$ (Figure 5B). Depending on the type of effectors, different

\section{REFERENCES}

Ahn, B. Y., Saldanha-Gama, R. F. G., Rahn, J. J., Hao, X., Zhang, J., Dang, N. H., et al. (2016). Glioma invasion mediated by the p75 neurotrophin receptor (p75NTR/CD271) requires regulated interaction with PDLIM1. Oncogene 35, 1411-1422. doi: 10.1038/onc.2015.199

Aloe, L. (2004). Rita Levi-Montalcini: the discovery of nerve growth factor and modern neurobiology. Trends Cell Biol. 14, 395-399. doi: 10.1016/j.tcb.2004. 05.011 signaling pathways may be activated, leading to the same migration and invasion effect. In some cases, proNTs (proNGF and proBDNF) may replace the NT effect through $\mathrm{p} 75^{\mathrm{NTR}}$ and sortilin activation (Figures 5A,B). From NCC migration and invasion, we learned that ephrin and cadherin are two important groups of membrane proteins that regulate mechanisms of cell invasion and migration through $\mathrm{p} 75^{\mathrm{NTR}}$. However, signaling pathways involved in such processes are still unknown. What we could suggest from cancer cell migration studies is that in the presence of the BDNF, p75 ${ }^{\mathrm{NTR}}$ may be activated by TrkB and Kidins220 upon ephrin receptor phosphorylation leading to STAT3 activation and RhoA inhibition. Likewise, in the presence of the NGF, p75 ${ }^{\mathrm{NTR}} / \mathrm{TrkA} /$ Kidins 220 may be activated upon ephrin receptor phosphorylation leading to MAPK/ERK pathway activation. Likewise, nothing is known about proNGF or proBDNF and sortilin effects on NCC migration and invasion.

Moreover, even if multiple clues implicate $\mathrm{p} 75^{\mathrm{NTR}}$ in cancer cell migration, questions regarding the exact roles of this receptor are still numerous. The first question could be related to the mode of regulation of $\mathrm{p} 75^{\mathrm{NTR}}$ functions. During migration, in normal and pathological conditions, $\mathrm{p} 75^{\mathrm{NTR}}$ could act through several pathways including direct interaction with neurotrophins, modulation of NT affinity of other receptors through a direct or indirect contact with those receptors, and through the release of ECD or ICD upon secretase cleavages. The second question relates to the origin of external factors like NTs that will activate p $75^{\mathrm{NTR}}$. Are those factors present in endogenous normal cells or only in modified pathological environments? All these questions appear more and more pertinent and would require an urgent response as they could pave the way to set up new targeted therapeutic approaches.

\section{AUTHOR CONTRIBUTIONS}

SW conceived and designed the presented idea and provided administrative support. SW and BR provided financial support. SW, GV, and BR contributed to the writing of the manuscript.

\section{FUNDING}

This work was supported by a grant from the Fonds National de la Recherche Scientifique (FNRS) of Belgium, by the TELEVIE (FNRS) of Belgium, by the Léon Frédéricq Foundation and by the Fonds Spéciaux à la Recherche of the University of Liège.

Alshehri, M. M., Robbins, S. M., and Senger, D. L. (2017). The role of neurotrophin signaling in gliomagenesis: a focus on the p75 neurotrophin receptor (p75NTR/CD271). Vitam. Horm. 104, 367-404. doi: 10.1016/bs.vh. 2016.11.001

Atapattu, L., Lackmann, M., and Janes, P. W. (2014). The role of proteases in regulating Eph/ephrin signaling. Cell Adh. Migr. 8, 294-307. doi: 10.4161/ 19336918.2014.970026

Baker, R. K., and Antin, P. B. (2003). Ephs and ephrins during early stages of chick embryogenesis. Dev. Dyn. 228, 128-142. doi: 10.1002/dvdy.10354 
Baldwin, A. N., Bitler, C. M., Welcher, A. A., and Shooter, E. M. (1992). Studies on the structure and binding properties of the cysteine-rich domain of rat low affinity nerve growth factor receptor (p75NGFR). J. Biol. Chem. 267, 8352-8359.

Bapat, A. A., Munoz, R. M., Von Hoff, D. D., and Han, H. (2016). Blocking nerve growth factor signaling reduces the neural invasion potential of pancreatic cancer cells. PLoS One 11:e0165586. doi: 10.1371/journal.pone.0165586

Barde, Y. A., Edgar, D., and Thoenen, H. (1982). Purification of a new neurotrophic factor from mammalian brain. EMBO J. 1, 549-553.

Becker, S. F. S., Mayor, R., and Kashef, J. (2013). Cadherin-11 mediates contact inhibition of locomotion during Xenopus neural crest cell migration. PLoS One 8:e85717. doi: 10.1371/journal.pone.0085717

Bentley, C. A., and Lee, K.-F. (2000). p75 is important for axon growth and schwann cell migration during development. J. Neurosci. 20, 7706-7715. doi: 10.1523/JNEUROSCI.20-20-07706.2000

Berghoff, J., Jaisimha, A. V., Duggan, S., MacSharry, J., and McCarthy, J. V. (2015). Gamma-secretase-independent role for cadherin-11 in neurotrophin receptor p75 (p75NTR) mediated glioblastoma cell migration. Mol. Cell. Neurosci. 69, 41-53. doi: 10.1016/j.mcn.2015.10.003

Birtolo, C., Pham, H., Morvaridi, S., Chheda, C., Go, V. L. W., Ptasznik, A., et al. (2017). Cadherin-11 is a cell surface marker up-regulated in activated pancreatic stellate cells and is involved in pancreatic cancer cell migration. Am. J. Pathol. 187, 146-155. doi: 10.1016/j.ajpath.2016.09.012

Bogenmann, E., Thomas, P. S., Li, Q., Kim, J., Yang, L.-T., Pierchala, B., et al. (2011). Generation of mice with a conditional allele for the p75(NTR) neurotrophin receptor gene. Genesis 49, 862-869. doi: 10.1002/dvg.20747

Bong, Y.-S., Lee, H.-S., Carim-Todd, L., Mood, K., Nishanian, T. G., Tessarollo, L., et al. (2007). ephrinB1 signals from the cell surface to the nucleus by recruitment of STAT3. Proc. Natl. Acad. Sci. U.S.A. 104, 17305-17310. doi: 10.1073/pnas. 0702337104

Cai, D., Chen, S.-C., Prasad, M., He, L., Wang, X., Choesmel-Cadamuro, V., et al. (2014). Mechanical feedback through E-cadherin promotes direction sensing during collective cell migration. Cell 157, 1146-1159. doi: 10.1016/j.cell.2014. 03.045

Cai, S., Cai, J., Jiang, W., and Ye, L. (2017). Kidins220 and tumor development: insights into a complexity of cross-talk among signalling pathways (Review). Int. J. Mol. Med. 40, 965-971. doi: 10.3892/ijmm.2017.3093

Cao, H. H., Chu, J. H., Kwan, H. Y., Su, T., Yu, H., Cheng, C. Y., et al. (2016). Inhibition of the STAT3 signaling pathway contributes to apigenin-mediated anti-metastatic effect in melanoma. Sci. Rep. 6:21731. doi: 10.1038/srep21731

Chang, M. S., Arevalo, J. C., and Chao, M. V. (2004). Ternary complex with Trk, p75, and an ankyrin-rich membrane spanning protein. J. Neurosci. Res. 78, 186-192. doi: 10.1002/jnr.20262

Chiaretti, A., Aloe, L., Antonelli, A., Ruggiero, A., Piastra, M., Riccardi, R., et al. (2004). Intraventricular nerve growth factor infusion improves cerebral blood flow and stimulates doublecortin expression in two infants with hypoxic-ischemic brain injury. Childs Nerv. Syst. 20:412. doi: 10.1179/ $016164107 X 247948$

Cho, M. S., Rupaimoole, R., Choi, H.-J., Noh, K., Chen, J., Hu, Q., et al. (2016). Complement component 3 is regulated by TWIST1 and mediates epithelialmesenchymal transition. J. Immunol. 196, 1412-1418. doi: 10.4049/jimmunol. 1501886

Chopin, V., Lagadec, C., Toillon, R., and Le Bourhis, X. (2016). Neurotrophin signaling in cancer stem cells. Cell. Mol. Life Sci. 73, 1859-1870. doi: 10.1007/ s00018-016-2156-7

Clay, M. R., and Halloran, M. C. (2014). Cadherin 6 promotes neural crest cell detachment via F-actin regulation and influences active Rho distribution during epithelial-to-mesenchymal transition. Development 141, 2506-2515. doi: 10. 1242/dev.105551

Coste, C., Neirinckx, V., Gothot, A., Wislet, S., and Rogister, B. (2015). Are neural crest stem cells the missing link between hematopoietic and neurogenic niches? Front. Cell Neurosci. 9:218. doi: 10.3389/fncel.2015.00218

De la Cruz-Morcillo, M. A., Berger, J., Sánchez-Prieto, R., Saada, S., Naves, T., Guillaudeau, A., et al. (2016). p75 neurotrophin receptor and pro-BDNF promote cell survival and migration in clear cell renal cell carcinoma. Oncotarget 5, 34480-34497. doi: 10.18632/oncotarget.8911

Faulkner, S., Jobling, P., Rowe, C. W., Rodrigues Oliveira, S. M., Roselli, S., Thorne, R. F., et al. (2018). Neurotrophin Receptors TrkA, p75NTR, and Sortilin Are Increased and Targetable in Thyroid Cancer. Am. J. Pathol. 188, 229-241. doi: 10.1016/j.ajpath.2017.09.008
Firulli, A. B., and Conway, S. J. (2008). Phosphoregulation of Twist1 provides a mechanism of cell fate control. Curr. Med. Chem. 15, 2641-2647. doi: 10.2174/ 092986708785908987

Forsyth, P. A., Krishna, N., Lawn, S., Valadez, J. G., Qu, X., Fenstermacher, D. A., et al. (2014). P75 neurotrophin receptor cleavage by A- and $\Gamma$ secretases is required for neurotrophin-mediated proliferation of brain tumor-initiating cells. J. Biol. Chem. 289, 8067-8085. doi: 10.1074/jbc.M113. 513762

Frisch, S. M., Schaller, M., and Cieply, B. (2013). Mechanisms that link the oncogenic epithelial-mesenchymal transition to suppression of anoikis. J. Cell Sci. 126, 21-29. doi: 10.1242/jcs.120907

Fujita, K., Ogawa, R., and Ito, K. (2016). CHD7, Oct3/4, Sox2, and Nanog control FoxD3 expression during mouse neural crest-derived stem cell formation. FEBS J. 283, 3791-3806. doi: 10.1111/febs.13843

Garcia-Garcia, A., de Castillejo, C. L. F., and Mendez-Ferrer, S. (2015). BMSCs and hematopoiesis. Immunol. Lett. 168, 129-135. doi: 10.1016/j.imlet.2015.06.020

Gaultier, A., Cousin, H., Darribère, T., and Alfandari, D. (2002). ADAM13 disintegrin and cysteine-rich domains bind to the second heparin-binding domain of fibronectin. J. Biol. Chem. 277, 23336-23344. doi: 10.1074/jbc. M201792200

Glejzer, A., Neirinckx, V., Rogister, B., and Wislet-Gendebien, S. (2011). "Neural crest stem cells from adult bone marrow: a new source for cell replacement therapy?" in Advances in Regenerative Medicine, ed. S. Wislet-Gendebien InTech: London. Available at: http://www.intechopen.com/books/advances-inregenerative-medicine/neural-crest-stem-cells-from-adultbone-\%marrow-anew-source-for-cell-replacement-therapy

Gomez, D. R., Byers, L. A., Nilsson, M., Diao, L., Wang, J., Li, L., et al. (2018). Integrative proteomic and transcriptomic analysis provides evidence for TrkB (NTRK2) as a therapeutic target in combination with tyrosine kinase inhibitors for non-small cell lung cancer. Oncotarget 9, 14268-14284. doi: 10.18632/ oncotarget.24361

He, J. Y., Han, P., Zhang, Y., Song, S. J., Feng, G. K., An, Y., et al. (2018) Overexpression of Nogo receptor $3(\mathrm{NgR} 3)$ correlates with poor prognosis and contributes to the migration of epithelial cells of nasopharyngeal carcinoma patients. J. Mol. Med. 96, 265-279. doi: 10.1007/s00109-0171618-1

He, X. L., Bazan, J. F., McDermott, G., Park, J. B., Wang, K., Tessier-Lavigne, M., et al. (2003). Structure of the Nogo receptor ectodomain: a recognition module implicated in myelin inhibition. Neuron 38, 177-185. doi: 10.1016/S08966273(03)00232-0

Heuer, J. G., Fatemie-Nainie, S., Wheeler, E. F., and Bothwell, M. (1990). Structure and developmental expression of the chicken NGF receptor. Dev. Biol. 137, 287-304. doi: 10.1016/0012-1606(90)90255-H

Hua, Z., Gu, X., Dong, Y., Tan, F., Liu, Z., Thiele, C. J., et al. (2016). PI3K and MAPK pathways mediate the BDNF/TrkB-increased metastasis in neuroblastoma. Tumor Biol. 37, 16227-16236. doi: 10.1007/s13277-0165433-z

Huang, E. J., and Reichardt, L. F. (2001). Neurotrophins: roles in neuronal development and function. Annu. Rev. Neurosci. 24, 677-736. doi: 10.1146/ annurev.neuro.24.1.677

Ip, N. Y., Ibáñez, C. F., Nye, S. H., McClain, J., Jones, P. F., Gies, D. R., et al. (1992). Mammalian neurotrophin-4: structure, chromosomal localization, tissue distribution, and receptor specificity. Proc. Natl. Acad. Sci. U.S.A. 89, 3060-3064. doi: 10.1073/pnas.89.7.3060

Ivanov, S. V., Panaccione, A., Brown, B., Guo, Y., Moskaluk, C. A., Wick, M. J., et al. (2013). TrkC signaling is activated in adenoid cystic carcinoma and requires NT-3 to stimulate invasive behavior. Oncogene 32, 3698-3710. doi: 10.1038/onc. 2012.377

Jia, S., Wang, W., Hu, Z., Shan, C., Wang, L., Wu, B., et al. (2015). BDNF mediated TrkB activation contributes to the EMT progression and the poor prognosis in human salivary adenoid cystic carcinoma. Oral Oncol. 51, 64-70. doi: 10.1016/j.oraloncology.2014.10.008.

Jiang, L., Wang, Z., Liu, C., Gong, Z., Yang, Y., Kang, H., et al. (2017). TrkB promotes laryngeal cancer metastasis via activation PI3K/AKT pathway. Oncotarget 8, 108726-108737. doi: 10.18632/oncotarget. 21711

Jiang, X., Rowitch, D. H., Soriano, P., McMahon, A. P., and Sucov, H. M. (2000). Fate of the mammalian cardiac neural crest. Development 127, 1607-1616. doi: $10.1038 /$ ncb3294 
Jin, H., Pan, Y., He, L., Zhai, H., Li, X., Zhao, L., et al. (2007). p75 neurotrophin receptor inhibits invasion and metastasis of gastric cancer. Mol. Cancer Res. 5, 423-433. doi: 10.1158/1541-7786.MCR-06-0407

Jin, S. G., Ryu, H. H., Li, S. Y., Li, C. H., Lim, S. H., Jang, W. Y., et al. (2016). Nogo-A inhibits the migration and invasion of human malignant glioma U87MG cells. Oncol. Rep. 35, 3395-3402. doi: 10.3892/or.2016.4737

Kanda, M., and Kodera, Y. (2016). Molecular mechanisms of peritoneal dissemination in gastric cancer. World J. Gastroenterol. 22, 6829-6840. doi: 10.3748/wjg.v22.i30.6829

Ke, H., Zhao, L., Zhang, H., Feng, X., Xu, H., Hao, J., et al. (2018). Loss of TDP43 inhibits progression of triple-negative breast cancer in coordination with SRSF3. Proc. Natl. Acad. Sci. U.S.A. 115, E3426-E3435. doi: 10.1073/pnas. 1714573115

Khan, M. A., Chen, H. C., Zhang, D., and Fu, J. (2013). Twist: a molecular target in cancer therapeutics. Tumour Biol. 34, 2497-2506. doi: 10.1007/s13277-0131002-x

Kim, N.-H., Choi, S.-H., Lee, T. R., Lee, C.-H., and Lee, A.-Y. (2014). Cadherin 11, a miR-675 target, induces N-Cadherin expression and epithelial-Mesenchymal transition in Melasma. J. Invest. Dermatol. 134, 2967-2976. doi: 10.1038/jid. 2014.257

Kong, H., Boulter, J., Weber, J. L., Lai, C., and Chao, M. V. (2001). An evolutionarily conserved transmembrane protein that is a novel downstream target of neurotrophin and ephrin receptors. J. Neurosci. 21, 176-185. doi: 10.1523/ JNEUROSCI.21-01-00176.2001

Kumar, S., Park, S. H., Cieply, B., Schupp, J., Killiam, E., Zhang, F., et al. (2011). A Pathway for the Control of Anoikis Sensitivity by E-Cadherin and Epithelialto-Mesenchymal Transition. Mol. Cell. Biol. 31, 4036-4051. doi: 10.1128/MCB. 01342-10

Kupferman, M., Jiffar, T., El-Naggar, A., Yilmaz, T., Zhou, G., Xie, T., et al. (2010). TrkB induces EMT and has a key role in invasion of head and neck squamous cell carcinoma. Oncogene 29, 2047-2059. doi: 10.1038/onc.2009.486

Lagadec, C., Meignan, S., Adriaenssens, E., Foveau, B., Vanhecke, E., Romon, R., et al. (2009). TrkA overexpression enhances growth and metastasis of breast cancer cells. Oncogene 28, 1960-1970. doi: 10.1038/onc.2009.61

Lee, R., Kermani, P., Teng, K. K., and Hempstead, B. L. (2001). Regulation of cell survival by secreted proneurotrophins. Science 294, 1945-1948. doi: 10.1126/ science. 1065057

Li, Y., Guo, Z., Chen, H., Dong, Z., Pan, Z. K., Ding, H., et al. (2011). HOXC8dependent cadherin 11 expression facilitates breast cancer cell migration through trio and rac. Genes Cancer 2, 880-888. doi: 10.1177/1947601911433129

Li, Z., Takenobu, H., Setyawati, A. N., Akita, N., Haruta, M., Satoh, S., et al. (2018). EZH2 regulates neuroblastoma cell differentiation via NTRK1 promoter epigenetic modifications. Oncogene 37, 2714-2727. doi: 10.1038/s41388-018$0133-3$

Liao, Y. H., Hsu, S. M., Yang, H. L., Tsai, M. S., and Huang, P. H. (2011). Upregulated ankyrin repeat-rich membrane spanning protein contributes to tumour progression in cutaneous melanoma. Br. J. Cancer 104, 982-988. doi: $10.1038 /$ bjc. 2011.18

Lin, K. T., Sloniowski, S., Ethell, D. W., and Ethell, I. M. (2008). Ephrin-B2-induced cleavage of EphB2 receptor is mediated by matrix metalloproteinases to trigger cell repulsion. J. Biol. Chem. 283, 28969-28979. doi: 10.1074/jbc.M804401200

Lin, Z., Tann, J. Y., Goh, E. T. H., Kelly, C., Lim, K. B., Gao, J. F., et al. (2015). Structural basis of death domain signaling in the p75 neurotrophin receptor. eLife 4:e11692. doi: 10.7554/eLife.11692

Lombard, A., Goffart, N., and Rogister, B. (2015). Glioblastoma circulating cells: reality, trap or illusion? Stem Cells Int. 2015:182985. doi: 10.1155/2015/182985

Maisonpierre, P. C., Le Beau, M. M., Espinosa, R., Ip, N. Y., Belluscio, L., de la Monte, S. M., et al. (1991). Human and rat brain-derived neurotrophic factor and neurotrophin-3: gene structures, distributions, and chromosomal localizations. Genomics 10, 558-568. doi: 10.1016/0888-7543(91) 90436-I

Marler, K. J. M., Poopalasundaram, S., Broom, E. R., Wentzel, C., and Drescher, U. (2010). Pro-neurotrophins secreted from retinal ganglion cell axons are necessary for ephrinA-p75 NTR -mediated axon guidance. Neural. Dev. 5:30. doi: 10.1186/1749-8104-5-30

Mathavan, K., Khedgikar, V., Bartolo, V., and Alfandari, D. (2017). The ectodomain of cadherin-11 binds to erbB2 and stimulates Akt phosphorylation to promote cranial neural crest cell migration. PLoS One 12:e0188963. doi: 10.1371/journal. pone. 0188963
Meeker, R., and Williams, K. (2014). Dynamic nature of the p75 neurotrophin receptor in response to injury and disease. J. Neuroimmune Pharmacol. 9, 615-628. doi: 10.1007/s11481-014-9566-9

Mochizuki, M., Tamai, K., Imai, T., Sugawara, S., Ogama, N., Nakamura, M., et al. (2016). CD271 regulates the proliferation and motility of hypopharyngeal cancer cells. Sci. Rep. 6:30707. doi: 10.1038/srep30707

Molloy, N. H., Read, D. E., and Gorman, A. M. (2011). Nerve growth factor in cancer cell death and survival. Cancers 3, 510-530. doi: 10.3390/cancers3010510

Moore, R., Theveneau, E., Pozzi, S., Alexandre, P., Richardson, J., Merks, A., et al. (2013). Par3 controls neural crest migration by promoting microtubule catastrophe during contact inhibition of locomotion. Development 140, 47634775. doi: 10.1242/dev.098509

Morrison, J. A., Mclennan, R., Wolfe, L. A., Gogol, M. M., Meier, S., McKinney, M. C., et al. (2017). Single-cell transcriptome analysis of avian neural crest migration reveals signatures of invasion and molecular transitions. eLife 6:e28415. doi: 10.7554/eLife.28415

Nakada, M., Anderson, E. M., Demuth, T., Nakada, S., Reavie, L. B., Drake, K. L., et al. (2010). The phosphorylation of ephrin-B2 ligand promotes glioma cell migration and invasion. Int. J. Cancer 126, 1155-1165. doi: 10.1002/ijc.24849

Nakada, M., Drake, K. L., Nakada, S., Niska, J. A., and Berens, M. E. (2006). EphrinB3 ligand promotes glioma invasion through activation of Rac1. Cancer Res. 66, 8492-8500. doi: 10.1158/0008-5472.CAN-05-4211

Nakamura, H., Nagasaka, K., Kawana, K., Taguchi, A., Uehara, Y., Yoshida, M., et al. (2016). Expression of Par3 polarity protein correlates with poor prognosis in ovarian cancer. BMC Cancer 16:897. doi: 10.1186/s12885-016-2929-2

Neubrand, V. E., Cesca, F., Benfenati, F., and Schiavo, G. (2012). Kidins220/ARMS as a functional mediator of multiple receptor signalling pathways. J. Cell Sci. 125, 1845-1854. doi: 10.1242/jcs.102764

Nykjaer, A., and Willnow, T. E. (2012). Sortilin: a receptor to regulate neuronal viability and function. Trends Neurosci. 35, 261-270. doi: 10.1016/j.tins.2012. 01.003

O’Leary, D. D. M., and Wilkinson, D. G. (1999). Eph receptors and ephrins in neural development. Curr. Opin. Neurobiol. 9, 65-73. doi: 10.1016/S09594388(99)80008-7

Pan, W., Kremer, K. L., Kaidonis, X., Ludlow, V. E., Rogers, M. L., Xie, J., et al. (2016). Characterization of p75 neurotrophin receptor expression in human dental pulp stem cells. Int. J. Dev. Neurosci. 53, 90-98. doi: 10.1016/j.ijdevneu. 2016.07.007

Patel, S. D., Chen, C. P., Bahna, F., Honig, B., and Shapiro, L. (2003). Cadherinmediated cell-cell adhesion: sticking together as a family. Curr. Opin. Struct. Biol. 13, 690-698. doi: 10.1016/j.sbi.2003.10.007

Pegoraro, C., and Monsoro-Burq, A. H. (2013). Signaling and transcriptional regulation in neural crest specification and migration: lessons from xenopus embryos. Wiley Interdiscip. Rev. Dev. Biol. 2, 247-259. doi: 10.1002/wdev.76

Peschon, J. J., Slack, J. L., Reddy, P., Stocking, K. L., Sunnarborg, S. W., Lee, D. C., et al. (1998). An essential role for ectodomain shedding in mammalian development. Science 282, 1281-1284. doi: 10.1126/science.282.5392.1281

Pramanik, S., Sulistio, Y. A., and Heese, K. (2016). Neurotrophin signaling and stem cells - implications for neurodegenerative diseases and stem cell therapy. Mol. Neurobiol. 54, 7401-7459. doi: 10.1007/s12035-016-0214-7

Prasad, M. S., and Paulson, A. F. (2011). A combination of enhancer/silencer modules regulates spatially restricted expression of cadherin-7 in neural epithelium. Dev. Dyn. 240, 1756-1768. doi: 10.1002/dvdy.22675

Raza, M.-Z., Allegrini, S., Dumontet, C., and Jordheim, L. P. (2017). Functions of the multi-interacting protein KIDINS220/ARMS in cancer and other pathologies. Genes Chromosomes Cancer 57, 114-122. doi: 10.1002/gcc.22514

Restivo, G., Diener, J., Cheng, P. F., Kiowski, G., Bonalli, M., Biedermann, T., et al. (2017). The low affinity neurotrophin receptor CD271 regulates phenotype switching in melanoma. Nat. Commun. 8:1988. doi: 10.1038/s41467017-01573-6

Ross, A. H., Grob, P., Bothwell, M., Elder, D. E., Ernst, C. S., Marano, N., et al. (1984). Characterization of nerve growth factor receptor in neural crest tumors using monoclonal antibodies. Proc. Natl. Acad. Sci. U.S.A. 81, 6681-6685. doi: $10.1073 /$ pnas.81.21.6681

Roycroft, A., and Mayor, R. (2016). Molecular basis of contact inhibition of locomotion. Cell. Mol. Life Sci. 73, 1119-1130. doi: 10.1007/s00018-015-2090-0

Saha, N., Kolev, M., and Nikolov, D. B. (2014). Structural features of the Nogo receptor signaling complexes at the neuron/myelin interface. Neurosci. Res. 87, 1-7. doi: 10.1016/j.neures.2014.06.003 
Satcher, R. L., Pan, T., Bilen, M. A., Li, X., Lee, Y.-C., Ortiz, A., et al. (2015). Cadherin-11 endocytosis through binding to clathrin promotes cadherin-11mediated migration in prostate cancer cells. J. Cell Sci. 128, 4629-4641. doi: $10.1242 /$ jcs. 176081

Schmieg, N., Thomas, C., Yabe, A., Lynch, D. S., Iglesias, T., Chakravarty, P., et al. (2015). Novel Kidins220/ARMS splice isoforms: potential specific regulators of neuronal and cardiovascular development. PLoS One 10:e0129944. doi: 10. 1371/journal.pone.0129944

Shelton, E. L., and Yutzey, K. E. (2008). Twist 1 function in endocardial cushion cell proliferation, migration, and differentiation during heart valve development. Dev. Biol. 317, 282-295. doi: 10.1016/j.ydbio.2008.02.037

Shimizu, D., Kanda, M., Sugimoto, H., Sueoka, S., Takami, H., Ezaka, K., et al. (2016). NRAGE promotes the malignant phenotype of hepatocellular carcinoma. Oncol. Lett. 11, 1847-1854. doi: 10.3892/ol.2016.4120

Shonukan, O., Bagayogo, I., McCrea, P., Chao, M., and Hempstead, B. (2003). Neurotrophin-induced melanoma cell migration is mediated through the actin-bundling protein fascin. Oncogene 22, 3616-3623. doi: 10.1038/sj.onc.12 06561

Skeldal, S., Matusica, D., Nykjaer, A., and Coulson, E. J. (2011). Proteolytic processing of the $\mathrm{p} 75$ neurotrophin receptor: a prerequisite for signalling?: neuronal life, growth and death signalling are crucially regulated by intramembrane proteolysis and trafficking of p75NTR. Bioessays 33, 614-625. doi: 10.1002/bies.201100036

Smeets, B., Alert, R., Pešek, J., Pagonabarraga, I., Ramon, H., and Vincent, R. (2016). Emergent structures and dynamics of cell colonies by contact inhibition of locomotion. Proc. Natl. Acad. Sci. U.S.A. 113, 14621-14626. doi: 10.1073/ pnas. 1521151113

Song, H., and Moon, A. (2006). Glial cell-derived neurotrophic factor (GDNF) promotes low-grade Hs683 glioma cell migration through JNK, ERK-1/2 and p38 MAPK signaling pathways. Neurosci. Res. 56, 29-38. doi: 10.1016/j.neures. 2006.04.019

Steinle, J. J., Meininger, C. J., Forough, R., Wu, G., Wu, M. H., and Granger, H. J. (2002). Eph B4 receptor signaling mediates endothelial cell migration and proliferation via the phosphatidyl-inositol 3-kinase pathway. J. Biol. Chem. 277, 43830-43835. doi: 10.1074/jbc.M207221200

Suraneni, M. V., and Badeaux, M. D. (2013). Tumor-Initiating Cells, Cancer Metastasis and Therapeutic Implications. Available at: https://www.ncbi.nlm. nih.gov/books/NBK169227/

Sutter, A., Riopelle, R. J., Harris, R. M., and Warrick, E. M. (1979). Shooter nerve growth factor receptors. characterization of two distinct classes of binding sites on chick embryo sensory ganglia cells. J. Biol. Chem. 254, 5972-5982.

Tep, C., Kim, M. L., Opincariu, L. I., Limpert, A. S., Chan, J. R., Appel, B., et al. (2012). Brain-derived neurotrophic factor (BDNF) induces polarized signaling of small GTPase (Rac1) protein at the onset of schwann cell myelination through partitioning-defective 3 (Par3) protein. J. Biol. Chem. 287, 1600-1608. doi: $10.1074 /$ jbc.M111.312736

Theveneau, E., and Mayor, R. (2012). Neural crest delamination and migration: from epithelium-to-mesenchyme transition to collective cell migration. Dev. Biol. 366, 34-54. doi: 10.1016/j.ydbio.2011.12.041

Truzzi, F., Marconi, A., Lotti, R., Dallaglio, K., French, L. E., Hempstead, B. L., et al. (2008). Neurotrophins and their receptors stimulate melanoma cell proliferation and migration. J. Invest. Dermatol. 128, 2031-2040. doi: 10.1038/ jid.2008.21

Vega-Lopez, G. A., Cerrizuela, S., and Aybar, M. J. (2017). Trunk neural crest cells: formation, migration and beyond. Int. J. Dev. Biol. 61, 5-15. doi: 10.1387/ijdb. $160408 \mathrm{gv}$

Vincentz, J. W., Barnes, R. M., Rodgers, R., Firulli, B. A., Conway, S. J., and Firulli, A. B. (2008). An absence of Twistl results in aberrant cardiac neural crest morphogenesis. Dev. Biol. 320, 131-139. doi: 10.1016/j.ydbio.2008. 04.037

Wang, B., Fujisawa, H., Zhuang, L., Kondo, S., Shivji, G. M., Kim, C. S., et al. (1997). Depressed langerhans cell migration and reduced contact hypersensitivity response in mice lacking tnf receptor p75. J. Immunol. 159, 6148-6155.
Wang, B., Lindley, L. E., Fernandez-Vega, V., Rieger, M. E., Sims, A. H., and Briegel, K. J. (2012). The T Box transcription factor TBX2 promotes epithelialmesenchymal transition and invasion of normal and malignant breast epithelial cells. PLoS One 7:e41355. doi: 10.1371/journal.pone.0041355

Wang, L., Rahn, J. J., Lun, X., Sun, B., Kelly, J. J. P., Weiss, S., et al. (2008). Gamma-Secretase represents a therapeutic target for the treatment of invasive glioma mediated by the p75 neurotrophin receptor. PLoS Biol. 6:e289. doi: 10.1371/journal.pbio.0060289

Wang, T.-C., Luo, S., Lin, C.-L., Chang, P.-J., and Chen, M.-F. (2015). Modulation of p75 neurotrophin receptor under hypoxic conditions induces migration and invasion of C6 glioma cells. Clin. Exp. Metastasis 32, 73-81. doi: 10.1007/ s10585-014-9692-Z

Wei, S., Xu, G., Bridges, L. C., Williams, P., White, J. M., and DeSimone, D. W. (2010). ADAM13 induces cranial neural crest by cleaving class $b$ ephrins and regulating Wnt signaling. Dev. Cell 19, 345-352. doi: 10.1016/j.devcel.2010. 07.012

Wilson, C. M., Naves, T., Saada, S., Pinet, S., Vincent, F., Lalloué, F., et al. (2014). The implications of sortilin/vps10p domain receptors in neurological and human diseases. CNS Neurol. Disord. Drug Targets 13, 1354-1365. doi: $10.2174 / 1871527313666141023151642$

Xi, R., Pan, S., Chen, X., Hui, B., Zhang, L., Fu, S., et al. (2016). HPV16 E6E7 induces cancer stem-like cells phenotypes in esophageal squamous cell carcinoma through the activation of PI3K/Akt signaling pathway in vitro and in vivo. Oncotarget 7, 57050-57065. doi: 10.18632/oncotarget.10959

Xiong, H., Nie, X., Zou, Y., Gong, C., Li, Y., Wu, H., et al. (2017). Twistl enhances hypoxia induced radioresistance in cervical cancer cells by promoting nuclear EGFR localization. J. Cancer 8, 345-353. doi: 10.7150/jca.16607

Xiong, J., Zhou, L., Yang, M., Lim, Y., Zhu, Y. H., Fu, D. L., et al. (2013). ProBDNF and its receptors are upregulated in glioma and inhibit the growth of glioma cells in vitro. Neuro Oncol. 15, 990-1007. doi: 10.1093/neuonc/ not039

Yang, N. Y., Pasquale, E. B., Owen, L. B., and Ethell, I. M. (2006). The EphB4 receptor-tyrosine kinase promotes the migration of melanoma cells through Rho-mediated actin cytoskeleton reorganization. J. Biol. Chem. 281, 32574-32586. doi: 10.1074/jbc.M604338200

Yap, A. S., and Kovacs, E. M. (2003). Direct cadherin-activated cell signaling. J. Cell Biol. 160, 11-16. doi: 10.1083/jcb.200208156

Yuanlong, H., Haifeng, J., Xiaoyin, Z., Jialin, S., Jie, L., Li, Y., et al. (2008). The inhibitory effect of p75 neurotrophin receptor on growth of human hepatocellular carcinoma cells. Cancer Lett. 268, 110-119. doi: 10.1016/j.canlet. 2008.03.038

Zanin, J. P., Battiato, N. L., and Rovasio, R. A. (2013). Neurotrophic factor NT-3 displays a non-canonical cell guidance signaling function for cephalic neural crest cells. Eur. J. Cell Biol. 92, 264-279. doi: 10.1016/j.ejcb.2013.10.006

Zhang, F., Yu, J., Yang, T., Xu, D., Chi, Z., Xia, Y., et al. (2016). A novel c-Jun $\mathrm{N}$-terminal kinase (JNK) signaling complex involved in neuronal migration during brain development. J. Biol. Chem. 291, 11466-11475. doi: 10.1074/jbc. M116.716811

Conflict of Interest Statement: The authors declare that the research was conducted in the absence of any commercial or financial relationships that could be construed as a potential conflict of interest.

The reviewer RU and handling Editor declared their shared affiliation at time of review.

Copyright $\odot 2018$ Wislet, Vandervelden and Rogister. This is an open-access article distributed under the terms of the Creative Commons Attribution License (CC BY). The use, distribution or reproduction in other forums is permitted, provided the original author(s) and the copyright owner(s) are credited and that the original publication in this journal is cited, in accordance with accepted academic practice. No use, distribution or reproduction is permitted which does not comply with these terms. 